\title{
Sequential Innovation and Optimal Patent Design
}

\author{
Christian Riis and Xianwen Shi*
}

August 3, 2012

\begin{abstract}
We study optimal patent design with sequential innovation. Firms innovate by undertaking "research" activities to generate new ideas and by undertaking "development" activities to transform these ideas into viable products. We characterize optimal patent policy, in particular, the tradeoff between patent length and breadth in this setting. We identify a "replacement effect" from the social planner's perspective: for given reward size, a better patent that generates higher social surplus is shorter but broader. The optimal patent breadth is independent of whether the current patent is expired or not. The optimal patent length may be finite.
\end{abstract}

${ }^{*}$ We thank Matthew Mitchell and Atle Seierstad for helpful comments, and Joaquin Poblete and Konstantinos Serfes for discussing the paper. Riis: Department of Economics, Norwegian Business School, Oslo, Norway; Email: christian.riis@bi.no. Shi: Department of Economics, University of Toronto, 150 St. George Street, Toronto, ON M5S 3G7, Canada; Email: xianwen.shi@utoronto.ca. 


\section{Introduction}

Innovation is the engine of economic growth. Innovation activities are only undertaken if an innovator can appropriate future benefits from its invention to cover its costs. In recognition of the possibility that without legal protection there will be too little innovation, the patent system was created to promote innovations by granting inventors an exclusive right (patent) to their inventions for a limited period of time. Patents foster innovation, facilitate commercialization and improve disclosure, but the resulted patent monopoly is associated with a variety of distortions. The tradeoff between standard deadweight loss and incentives for innovation is the focus of early patent design studies initiated by Nordhaus (1969) 1 They demonstrate how patent length should be chosen appropriately to balance incentives and deadweight loss.

The two-dimensional analysis used in these early studies, though insightful, is not adequate because both incentives and welfare costs are multidimensional. First, patents are granted after invention but before commercialization. By centering on pre-invention incentives, the early analysis ignores the impact of the patent on incentives for postinvention development. In addition, it considers only one innovator, so the welfare costs due to rent-seeking activities such as "patent races", which are often more significant than the standard deadweight loss, are not taken into account $2^{2}$ Second, there are policy instruments other than patent length, such as patent breadth and patent scope, which are arguably more important and are subject to more discretion than patent length. ${ }^{3}$ Third, innovation is often sequential, in the sense that new technologies build on existing ones. In the setting of sequential innovation, there is an additional welfare cost associated with patent monopoly because it may block future improvements. Since the early analysis is conducted in the context of one-time innovation, this additional welfare cost is not taken into account.

Subsequent contributions to the patent design literature have addressed in isolation the incentives for post-invention development, the tradeoff between patent length and patent breadth, and the nature of sequential innovation 4 This approach is not entirely satisfactory because these issues are closely connected. The goal of this paper is to conduct an integrated analysis of optimal patent policy, providing insight on how different incentives and welfare costs interact and how the level and decomposition of social value

\footnotetext{
${ }^{1}$ See also Scherer (1972) and Tandon (1982).

${ }^{2}$ Posner (1975) forcefully argues that the producer surplus or the rent captured by the monopolist should also be counted as part of the social costs of monopoly.

${ }^{3}$ See Merges and Nelson (1990) for an extensive discussion on the importance of patent breadth and patent scope in patent policy.

${ }^{4}$ We will discuss relevant literature shortly.
} 
of innovation factor into patent design. Our main finding is that it is optimal to reward innovations of higher social values with broader but shorter patents.

In order to study patent policy that provides innovators with incentives for both pre-invention research investment and post-invention commercialization investment, and that also takes into account the multidimensional welfare costs associated with patent monopoly, we introduce a model of dynamic innovation whose main components are:

1. Firms innovate by undertaking costly "research" activities to generate new ideas and by undertaking costly "development" activities to turn these ideas into viable products. The competition in research is modeled as "patent races" in order to capture the welfare cost due to competitive activities in seeking a patent monopoly. Both pre-invention and post-invention incentives are considered in our model.

2. Innovation is sequential and new products supersede old ones. That is, industry experiences ongoing series of acts of "creative destruction". Hence, our model considers the additional welfare cost due to the possible blocking of future improvements over the existing technology, in particular, the tradeoff between rewarding current innovators and rewarding future innovators.

3. The social planner chooses a set of instruments, which consists of an expiration time (patent length) and a possibly time-dependent patentability requirement (patent breadth), to maximize the total discounted social welfare, subject to a constraint that she must deliver patent rewards promised to earlier patents.

In our model, a large number of firms undertake "research" activities to generate new ideas which are heterogeneous in quality. We interpret ideas as initial inventions, so the heterogeneity of idea quality captures the fact that inventions may differ in terms of "novelty", "utility", and "nonobviousness". We assume free entry of research firms. A research firm with a new idea can apply for a patent. A patent allows the patentee to prevent its rivals from producing its patented product during the period that the patent is valid. Upon patent approval, the patentee then undertakes "development" activities to commercialize the patent. We assume that, once a new patent is filed, the current patent, if not yet expired, terminates immediately. In order to ease exposition and save notation, we primarily focus on a setting where innovation is radical in the sense that a new patented product priced at a monopoly price completely drives the old one out of market, although our analysis applies more generally.

A patent policy consists of an expiration time (not necessarily finite) for the current patent, and a sequence of patent reward functions for future ideas, one reward function for each time period. Specifically, the patent reward function for time $t$ specifies how 
much to reward a new idea with a particular quality arriving at time $t$. The size of the patent reward, or patent duration, is measured in terms of the discounted length of the period that the patent remains valid $5^{5}$ For each fixed time $t$, and for each given patent reward function, there is a cutoff such that only ideas with quality exceeding this cutoff are profitable for commercialization. We will refer to this cutoff as patent breadth at time $t$, while referring to the expiration time as patent length. Patent breadth is a patentability requirement such that a new idea is patentable (and profitable) only if it exceeds the quality threshold.

As pointed out in Gilbert and Shapiro (1990), patent policy can be decomposed into two parts: how to choose the reward size for each patent, and how to structure each given reward. We first characterize the socially optimal mix of patent length and breadth that delivers a given patent reward, and then build on this characterization to address the determination of optimal reward size.

Our characterization of the socially optimal mix between patent length and breadth relies on two technical innovations. First, we reformulate our planner's problem into a standard optimal control problem by using the arrival rate of patentable ideas as the control variable, so we can apply various versions of Arrow's sufficiency theorem to characterize the optimal policy when the instantaneous welfare flow is concave in the control variable $\sqrt[6]{6}$ If the instantaneous welfare flow is not concave, however, we cannot directly apply Arrow's sufficiency theorem. Our second innovation is to develop a method, what we call convex-envelope approach, to deal with possible non-concavity of the instantaneous welfare flow. This new approach not only simplifies our derivation but also provides intuition for an otherwise abstract control solution.

The optimal mix of patent length and breadth takes a simple form in our seemingly complex framework. The optimal patent length could be finite or infinite. First, if the size of a given reward is small and the social surplus generated by the current patent is high, the optimal policy is characterized by a finite patent length $T$ and one constant cutoff $\widehat{z}$. Only ideas with quality exceeding $\widehat{z}$ are patentable, and the current patent expires either when $T$ is reached or when a new patent is filed. Second, if the size of given reward is large and the social surplus generated by the current patent is low, the optimal patent length is infinite. The optimal policy is characterized either by a single cutoff or by two cutoffs plus a switching time between these two cutoffs, and the current patent expires

\footnotetext{
${ }^{5}$ O'Donoghue, Scotchmer and Thisse (1998) refer to the expiration time as the statutory patent life and the patent duration as the effective patent life.

${ }^{6}$ In particular, we uses three versions: finite horizon, infinite horizon, and free terminal time. Since our characterization is quite simple, our exercises may be of pedagogical interest as well.
} 
immediately after a new patent is filed.

It is worth noting that the tradeoff between patent length and breadth in the former case depends on the level rather than the decomposition of the social surplus. In particular, a better patent that generates a larger social surplus is shorter but broader. Moreover, the patent breadth (cutoff) $\widehat{z}$ does not jump (up or down) when the current patent expires at time $T$, i.e., the optimal policy maintains the same idea selection criterion regardless of the state (expired or not) of the current patent. To understand this intuitively, let us first consider the simpler scenario where all patents are expired. The product market is fully competitive so there is no deadweight loss. Therefore, the social surplus generated by the current (expired) patent is fully realized and accrues to consumers. The planner chooses idea selection criterion (cutoffs) to balance having a new innovation sooner versus having a better innovation. Note that, when waiting for the next innovation, she collects the social surplus generated by the current patent. If this social surplus is large, it is less costly for her to wait for better innovation. Hence, she will be more selective and thus set a higher cutoff (i.e., bigger patent breadth). In other words, there is a "replacement effect" from the planner's perspective, analogous to the standard Arrow's "replacement effect" from the incumbent's perspective.

Next consider the alternative scenario where there is an active patent. In this case, a feasible patent policy must deliver the patent duration promised to the current patent. The optimal patent length $T$ must be chosen such that the shadow price of this promisekeeping constraint equals exactly the flow deadweight loss. As a result, the welfare cost associated with patent monopoly, which equals the patent duration multiplying the shadow price, does not depend on the specific mix of patent length and breadth. This implies that, when choosing the cutoffs, the planner faces exactly the same tradeoff as in the case with no active patent. Therefore, the idea selection criterion must be the same before and after the patent expires, and the decomposition of the social surplus has no effect on choosing the cutoff.

Although the decomposition of the social surplus does not play a role in structuring a given reward, it is crucial in determining the optimal size of the reward. Building on the characterization of optimal patent length and breadth, we show that a patent should obtain a larger reward if its deadweight loss represents a smaller fraction of its social surplus.

Finally, we adapt our analysis to the incremental innovation setting where the pricing of the new product is constrained by the old ones. The optimal policy in this setting is similar to what we find in a radical innovation setting. The optimal patent breadth is constant, and different reward sizes are delivered by varying the patent length which could be finite or infinite. 
Our paper extends and complements earlier analyses of patent scope. Gilbert and Shapiro (1990) and Klemperer (1990) first introduce patent breadth into Naudhaus's framework to investigate the optimal mix of patent length and patent breadth that delivers a given patent reward. In a one-time innovation model with vertical variety, Gilbert and Shapiro show that optimal patents have infinite patent length and different reward sizes can be delivered by varying the patent breadth. In a one-time innovation model with horizontal variety, Klemperer provides conditions under which optimal patent length is finite and conditions under which optimal patent length is infinite $!^{7}$ Both papers, however, acknowledge that the assumption of single innovation is an important limitation in their analysis, and call for an extension of their analysis to multiple innovations. This paper introduces sequential innovation into the framework of Gilbert and Shapiro (1990), and shows that optimal patents can be finite. Furthermore, the relative size of deadweight loss (or the decomposition of social surplus) associated with patents does not play a role in optimal structuring a given reward 8

Our analysis also contributes to the rapidly growing literature on sequential innovations. Important papers in this area include Scotchmer (1991, 1996), Scotchmer and Green (1990), Green and Scotchmer (1996), Chang (1995), O’Donoghue (1998), O'Donoghue, Scotchmer, and Thisse (1998, OST hereafter), Hunt (2004), Hopenhayn, Llobet and Mitchell (2006, HLM hereafter), and Bessen and Maskin (2009), among others. O'Donoghue (1998), OST and HLM are the closest to our model. In a sequential innovation setting similar to ours, O'Donoghue (1998) shows that a minimal patentability requirement (patent breadth) can stimulate R\&D because it increases the length of market incumbency. But he considers only stationary policies with infinite patent length. We extend his analysis by considering a broader class of patent policies with time-dependent patent breadth and endogenous patent length. We characterize optimal patentability requirement and the tradeoff between patent length and breadth. $9^{9}$

OST find that a broad patent with a short statutory patent life improves the diffusion of new products, but a narrow patent with a long statutory patent life can lower R\&D costs. HLM adopt the mechanism design approach to characterize optimal patent policy

\footnotetext{
${ }^{7}$ Gallini (1992) introduces the possibility of costly imitation and shows that broad patents with finite patent lives can be optimal in the one-time innovation setting.

${ }^{8}$ O'Donoghue, Scotchmer, and Thisse (1998) distinguish two types of patent breadth: "lagging breadth" which protects against imitation, and "leading breadth" which protects against new innovations. According to this terminology, the patent breadth analyzed in Gilbert and Shapiro (1990) and Klemperer (1990) is more of a "lagging breadth" rather than a "leading breadth", which is the focus of this paper.

${ }^{9} \mathrm{We}$ find that if the patent length is exogenously fixed, the optimal patent breadth is often timedependent. It is stationary, however, when the patent length is endogenously chosen. Hence, the stationarity assumption in O'Donoghue (1998) is not without loss of generality.
} 
and find that the optimal patent policy is a menu of patents with infinite lengths but different breadths 10

Our model builds on OST and HLM, but differs from theirs in at least two significant ways. First, in OST and HLM (and O'Donoghue (1998)), consumers are homogenous and thus there is no deadweight loss associated with a patent monopoly. In contrast, we allow for a general form of monopoly inefficiency. Thus, the classical tradeoff between incentives for innovation and deadweight loss, important in our analysis, is absent in their models. Second, both OST and HLM focus on the incentives for post-invention development and ignore the incentives for initial invention. In particular, they assume that ideas are free and arrive exogenously. In our model, ideas are costly and the arrival process is endogenously determined by firms' research investments 11 As a result, our model can capture the additional welfare cost of a patent monopoly in the form of a monopoly rent (or producer surplus) which is dissipated through the rivalrous investments in research. Each feature has important policy implications. For example, unlike in HLM, the optimal patent length in our model can be finite or infinite.

We model the endogenous idea arrival process as a reduced-form patent race, following Acemoglu and Cao (2010). They study a general equilibrium model with innovation by both existing firms and entrants. The research and development in our model resembles their entrant and incumbent innovation, but we focus on patent design while they focus on the effect of innovation on growth and firm size distribution. Our paper is also related to the recent analysis of state-contingent patent policy by Acemoglu and Akcigit (2011) and Hopenhayn and Mitchell (2011). Both papers find that the optimal policy may favor the technology leader rather than the follower 12

The remainder of the paper is organized as follows. Section 2 sets up the model and formulates the planner's optimization problem. Section 3 contains the characterization of the optimal patent policy when there is no active patent. The characterization of the optimal patent policy with an active patent is carried out in Section 4 . Section 5 demonstrates how our analysis of radical innovation can be adapted to a setting with incremental innovation. Section 6 concludes. All the proofs are relegated to the Appendix.

\footnotetext{
${ }^{10}$ The mechanism design approach was introduced to the patent design literature by Cornelli and Schankerman (1999) and Scotchmer (1999).

${ }^{11}$ Banal-Estanol and Macho-Stadler (2010) and Scotchmer (2011) also make a distinction between research and development, but their focus is quite different from ours. They investigate how the government should subsidize research and development.

${ }^{12}$ There is a large literature on patent race, see for example, Dasgupta and Stiglitz (1980), Reinganum (1982), and Harris and Vickers (1987). Recent growth models that incoporate sequential innovations include Aghion, Harris and Vickers (1997), and Aghion, Harris, Howitt and Vickers (2001).
} 


\section{Model Setup}

Firms compete in innovation in continuous time. Innovation is sequential: new technologies must build on the old ones. The line of current and future products is modeled as a "quality ladder": a new product improves on the old one with higher quality or lower cost or both. To ease exposition, innovation is assumed to be radical in the economic sense: the new product completely drives out the old one at monopoly price. That is, the new product selling at monopoly price is more attractive than the old one selling at the marginal cost. We will remark later that this assumption is not critical for our analysis (see Section 4.2). In addition, Section 5 will show how our analysis can be easily adapted to the incremental innovation setting studied in HLM.

An innovation is carried out in two phases: a "research" phase to generate new ideas, and a subsequent "development" phase to commercialize these ideas. Both research and development activities, to be described below, are costly. The utilitarian social planner and firms discount the future with a common discount rate $r$.

\section{$2.1 \quad$ Research and Development}

Every innovation starts with a new idea which can be used to improve the state of the art, but new ideas are costly to generate. A large number of firms (or new entrants) invest in research to generate new ideas. Following Acemoglu and Cao (2010), we assume that the arrival rate of new ideas for each firm depends on both individual and aggregate research investment. Specifically, if firm $i$ invests $K_{i t}$ in research at time $t$, then firm $i$ has a flow rate of new ideas at time $t$ equal to $\lambda_{i t}=\gamma\left(K_{t}\right) K_{i t}$, where $K_{t}$ is the aggregate research investment incurred by all firms in the market at time $t$, i.e., $K_{t}=\sum_{i} K_{i t}$. We assume that $\gamma(\cdot)$ is continuous and strictly decreasing, which captures the idea that individual research investment imposes negative externality on other research firms. The negative externality may arise either because research firms draw ideas from a common idea pool or because they compete for the same pool of research talents. We assume that the size of individual investment $K_{i t}$ is small compared to the aggregate investment $K_{t}$, so all firms will take $K_{t}$ as given at time $t$. As a result, the individual arrival rate of new ideas to a firm is linear in its own research investment.

Let $\lambda_{t}$ denote the aggregate arrival rate of new ideas, that is, $\lambda_{t}=\sum_{i} \lambda_{i t}=K_{t} \gamma\left(K_{t}\right)$. We further assume that the aggregate arrival rate $\lambda_{t}$ is strictly increasing in the aggregate research investment $K_{t}$ and that the following Inada-type condition holds:

$$
\lim _{K_{t} \rightarrow 0} K_{t} \gamma\left(K_{t}\right) \rightarrow 0 \text { and } \lim _{K_{t} \rightarrow \infty} K_{t} \gamma\left(K_{t}\right) \rightarrow \infty
$$

Therefore, there is a unique $\lambda_{t}$ associated with each patent policy. We assume there is no 
fixed entry cost and research firms are free to enter and exit at any point in time.

Once a firm has an idea, it has to decide whether to invest in development to transform the idea into a viable product. An idea is either developed immediately or lost, i.e., banking ideas is not possible ${ }^{13}$ Moreover, a product can be freely imitated unless patented. Therefore, once a firm generates a new idea, if patentable, it will immediately apply for a patent and commercialize it. The profit flow generated by the new product $\widehat{\pi}(\kappa, z)$, is increasing in both the idea quality $z$ and the firm's development investment $\kappa$. The idea quality $z$ is independently drawn from a distribution $\Phi(z)$ with support $[0, \infty)$ and a density $\phi(z)>0$ for all $z$.

We will sometimes refer to the current patent holder at time $t$ as the incumbent at time $t$. Similar to OST and HLM, we assume that the incumbent, possibly due to the replacement effect, does not invest in research to generate new ideas to replace its own technology ${ }^{14}$ This assumption helps rule out the possibility that a single firm may hold two consecutive patents. It is a rather weak assumption in our setting because, given a large number of research firms, the probability that a particular firm will obtain the next patentable idea is negligible. If the patent policy is anonymous (i.e., independent of firms' identity), this assumption is innocuous: the incumbent indeed has no incentive to invest in research because of the replacement effect and the fact that the expected profit for each research firm is zero. This assumption is implicitly made in most of the patent design literature 15

The size of research investment, the size of development investment, and the idea arrival are the private information of respective firms, but the idea quality is assumed to be publicly observable when a firm applies for patent.16

\subsection{Patent Policy and R\&D Investment}

To provide firms with incentives to innovate, the social planner may grant a monopoly right (patent) to a new idea held by a firm, which prevents other firms from producing the patented product for a certain period of time. A patentee has market power on the patented product until its patent terminates. Once the patent expires, the technology becomes freely accessible and the price immediately drops to the level of marginal cost.

\footnotetext{
${ }^{13}$ See Erkal and Scotchmer (2009) for an analysis which allows innovators to bank ideas for future use.

${ }^{14}$ A similar assumption is made in Klette and Kortum (2004).

${ }^{15}$ A notable exception is Hopenhayn and Mitchell (2011) who study optimal patent policy in a setting where two long-lived firms innovate repeatedly. But for tractability purpose, they assume that ideas are homogeneous and the idea arrival process is exogenous.

${ }^{16}$ See HLM for an illustration of how a patent policy can be implemented with buyout schemes when the idea quality is privately observed. In a related setting, Kramer (1998) proposes a clever auction design to determine the private value of patents and thus facilitate the government to buy out patents.
} 
Let $z_{n}$ denote the idea of $n$-th patent which is currently active. Let $\rho_{n}$ denote the expected discounted length of the period that patent $z_{n}$ remains valid under a patent policy $\mathcal{P}$. That is, $\rho_{n}$ is the expected discount duration of market incumbency, which we also refer to as the patent duration of patent $z_{n}$. Consider the incentives for the patent holder to invest in development under policy $\mathcal{P}$. We assume that both consumer demand and production cost, conditional on product quality, do not vary over time, so the profit flow $\widehat{\pi}\left(\kappa, z_{n}\right)$ for patent $z_{n}$ is time-invariant during the period that patent $z_{n}$ is valid. Then the equilibrium discounted payoff to the patentee when development investment $\kappa$ is chosen optimally is

$$
\pi\left(\rho_{n}, z_{n}\right)=\max _{\kappa}\left[\widehat{\pi}\left(\kappa, z_{n}\right) \rho_{n}-\kappa\right] .
$$

The equilibrium development investment $\kappa\left(\rho_{n}, z_{n}\right)$ will be a function of $\rho_{n}$ and $z_{n}$.

Condition (1) reveals that patent duration $\rho_{n}$ plays a central role in the patentee's investment decision. First, to deliver this given reward $\rho_{n}$, the continuation play induced by policy $\mathcal{P}$ must be consistent with $\rho_{n}$. Hence, the patent duration plays a similar role in our setting as the "promised agent continuation utility" in the dynamic contracting framework (Spear and Srivastrava (1987), Sannikov (2008)). Second, for a fixed $z_{n}$, patent duration $\rho_{n}$ uniquely determines the equilibrium profits for the patent holder. Conditional on $\rho_{n}$ and $z_{n}$, the patentee's profit does not depend on the details of policy $\mathcal{P}$. Therefore, we can also refer to $\rho_{n}$ as the reward size for patent $z_{n}$. The planner's problem of optimal structuring a given reward $\rho_{n}$ is to find the optimal $\mathcal{P}$ that maximizes the discounted total social welfare and at the same time delivers $\rho_{n}$ to patent $z_{n}$.

We restrict attention to the class of patent policies under which a new idea is patentable only if it does not infringe upon earlier patents. Therefore, the blocking patent situation 17 described in Merges and Nelson (1990) is ruled out 18 This restriction, together with our radical innovation assumption, implies that the current patent, if not yet expired, terminates immediately after a new patent is approved, because the new patent is noninfringing and will supersede the existing product in the market.

The planner can choose two patent instruments: an expiration time $T$ for the current patent $z_{n}$ (patent length), and a patent reward function for future ideas which may depend on both idea quality and arrival time. Let $t$ denote the calender time since patent $z_{n}$ is approved. The patent reward function $\rho_{t}(\cdot)$ promises that if an idea $z$ files for a patent at time $t$ it will obtain a patent duration $\rho_{t}(z)$. Since the current patent terminates whenever

\footnotetext{
${ }^{17} \mathrm{~A}$ blocking patent is an earlier patent that must be licensed in order to market a later patent. This often occurs between an improvement patent and the original one, when an improvement is patented but the improvement patent infringes on the original one.

${ }^{18}$ Alternatively, we can assume that the current patent expires immediately after a new patent is filed, a class of patent policies that HLM refer to as "exclusive rights" policies.
} 
a new patent is filed, and a patentable idea may arrive before $T$, the current patent may terminate before $T$. OST call the expiration time as the statutory patent life and the patent duration as the effective patent life.

We further restrict attention to patent policies with weakly increasing $\rho_{t}(z){ }^{19}$ The familiar patent instrument, patent breadth, can then be derived from policy $\mathcal{P}=\left(T,\left\{\rho_{t}(z)\right\}_{t=0}^{\infty}\right)$ as follows. Let $\widehat{z}_{t}$ denote the minimal level of idea quality such that the patentee's profits $\pi\left(\rho_{t}\left(\widehat{z}_{t}\right), \widehat{z}_{t}\right) \geq 0$. Then a research firm with idea $z$ at time $t$ will file for a patent and commercialize it if and only if $z \geq \widehat{z}_{t}$. We interpret the cutoff $\widehat{z}_{t}$ as the patent breadth of the current patent at time $t$ (see Figure 1) 20

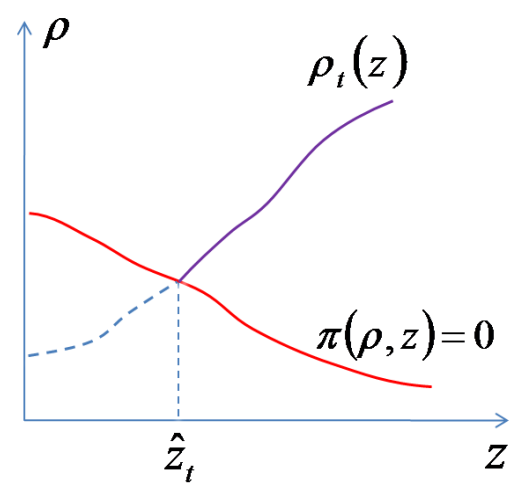

Figure 1: Patent breadth $\widehat{z}_{t}$ and reward function $\rho_{t}(z)$

When choosing policy $\mathcal{P}$, the planner must obey the following constraint: the policy $\mathcal{P}$ must deliver patent duration $\rho_{n}$ that she promises to the current patent $z_{n}$. Following HLM, we refer to this constraint as the "promise-keeping" constraint. Formally, a feasible patent policy $\mathcal{P}$ must satisfy

$$
\rho_{n}=\int_{0}^{T} e^{-\int_{0}^{s}\left(\lambda_{\tau}\left(1-\Phi\left(\widehat{z}_{\tau}\right)\right)+r\right) d \tau} d s,
$$

where $\lambda_{t}$ is the unique arrival rate of ideas at time $t$ under policy $\mathcal{P}{ }^{21}$ We will describe shortly how $\lambda_{t}$ relates to $\mathcal{P}$.

${ }^{19}$ Monotonicity is necessary for implementation (Cornelli and Schankerman 1999 and Scotchmer 1999).

${ }^{20}$ Our patent breadth is a leading breadth as defined in OST. It protects against new improved products.

${ }^{21}$ To understand this formula, let $\rho_{n t}$ denote the remaining duration of the current patent at time $t$. Then $\rho_{n t}$ can be written recursively as

$$
\rho_{n t}=d t+\lambda_{t}\left(1-\Phi\left(\widehat{z}_{t}\right)\right) d t \cdot 0+e^{-r d t}\left[1-\lambda_{t}\left(1-\Phi\left(\widehat{z}_{t}\right)\right) d t\right] \rho_{n t+d t} .
$$

Subtracting both sides by $e^{-r d t} \rho_{n t}$, dividing both sides by $d t$, and let $d t \rightarrow 0$, we have

$$
\dot{\rho}_{n t}-\left(\lambda_{t}\left(1-\Phi\left(\widehat{z}_{t}\right)\right)+r\right) \rho_{n t}=-1 .
$$

Using boundary condition $\rho_{n T}=0$, we can find the solution to the ordinary differential equation and obtain 2 by setting $t=0$. 
The timing of the game between the $n$-th and $(n+1)$-th patent approval is the following: Immediately after a firm files for patent $z_{n}$ and obtains protection $\rho_{n}$, the planner announces future patent policy $\mathcal{P}=\left\{T\left(\rho_{n}\right),\left\{\widehat{z}_{t}\left(\rho_{n}\right)\right\}_{t=0}^{\infty},\left\{\rho_{t}\left(\cdot, \rho_{n}\right)\right\}_{t=0}^{\infty}\right\}$ that is consistent with $\rho_{n}$. Then at time $t=0$ the current patent holder (incumbent) chooses a lump-sum development investment $\kappa$, and in every future period $t$ research firms decide whether to enter and how much to invest in research. The aggregate flow investment $K_{t}$ incurred by all research firms in period $t$ generates new ideas with aggregate arrival rate $\lambda_{t}=K_{t} \gamma\left(K_{t}\right)$. If no patentable idea arrives before the expiration date $T\left(\rho_{n}\right)$, the current patent expires at time $T$. If a firm gets an idea $z_{n+1}$ with $z_{n+1} \geq \widehat{z}_{t}$ at time $t$, either before $T$ or after $T$, the firm files a new patent and obtains protection $\rho_{t}\left(z_{n+1}, \rho_{n}\right)$, and the old patent $z_{n}$, if not yet expired, terminates immediately. The new patentee becomes the new incumbent. Now the new patent protection becomes $\rho_{n+1}=\rho_{t}\left(z_{n+1}, \rho_{n}\right)$. The planner then announces a new policy $\mathcal{P}^{\prime}=\left\{T\left(\rho_{n+1}\right),\left\{\widehat{z}_{t}\left(\rho_{n+1}\right)\right\}_{t=0}^{\infty},\left\{\rho_{t}\left(\cdot, \rho_{n+1}\right)\right\}_{t=0}^{\infty}\right\}$ that is consistent with $\rho_{n+1}$. The process repeats. ${ }^{22}$ For notational simplicity, we sometimes suppress the dependence of the patent policy instruments on $\rho_{n}$.

Next consider the entrants' incentives to invest in research. Under policy $\mathcal{P}$, the instantaneous payoff for firm $i$ at time $t$ is given by

$$
K_{i t} \gamma\left(K_{t}\right) \int_{\widehat{z}_{t}}^{\infty} \pi\left(\rho_{t}(\xi), \xi\right) \phi(\xi) d \xi-K_{i t}=K_{i t}\left[\gamma\left(K_{t}\right) \int_{\widehat{z}_{t}}^{\infty} \pi\left(\rho_{t}(\xi), \xi\right) \phi(\xi) d \xi-1\right]
$$

Free entry then implies that

$$
\begin{aligned}
& \gamma\left(K_{t}\right) \int_{\widehat{z}_{t}}^{\infty} \pi\left(\rho_{t}(\xi), \xi\right) \phi(\xi) d \xi \leq 1 \text { if } K_{i t}=0 \\
& \gamma\left(K_{t}\right) \int_{\widehat{z}_{t}}^{\infty} \pi\left(\rho_{t}(\xi), \xi\right) \phi(\xi) d \xi=1 \text { if } K_{i t}>0
\end{aligned}
$$

Therefore, if the equilibrium aggregate investment $K_{t}$ is positive, we can derive $K_{t}\left(\rho_{t}(\cdot), \widehat{z}_{t}\right)$ as a function of the reward function $\rho_{t}(\cdot)$ and the cutoff $\widehat{z}_{t}$ at time $t$.

It is useful to introduce the arrival rate of patentable ideas $u\left(\rho_{t}(\cdot), \widehat{z}_{t}\right)$ as

$$
u\left(\rho_{t}(\cdot), \widehat{z}_{t}\right) \equiv \lambda_{t}\left[1-\Phi\left(\widehat{z}_{t}\right)\right]
$$

Since $\gamma(\cdot)$ is assumed to be strictly decreasing, $K_{t}\left(\rho_{t}(\cdot), \widehat{z}_{t}\right)$ must be strictly decreasing in $\widehat{z}_{t}$. Hence, $\lambda_{t}=K_{t} \gamma\left(K_{t}\right)$ and $u\left(\rho_{t}(\cdot), \widehat{z}_{t}\right)$ are also strictly decreasing in $\widehat{z}_{t}$. To simplify notation, from now on, we will write $\lambda\left(\rho_{t}(\cdot), \widehat{z}_{t}\right) \equiv \lambda_{t}\left(K_{t}\left(\rho_{t}(\cdot), \widehat{z}_{t}\right)\right)$ and $u_{t} \equiv u\left(\rho_{t}(\cdot), \widehat{z}_{t}\right)$.

\footnotetext{
${ }^{22}$ Alternatively, the planner could commit to a patent policy that specifies a fully history-contingent sequence of expiration time and reward functions for all future patentable ideas, not just the next one. It is equivalent to our current formulation where the planner has to choose a new patent policy after every new patent approval.
} 


\subsection{The Patent Design Problem}

Suppose the current patent has idea quality $z_{n}$ and is promised a patent duration $\rho_{n}$. The social planner is utilitarian and chooses $\mathcal{P}$ to maximize the sum of the discounted payoff to incumbents, entrants (research firms), and consumers, subject to the promise-keeping constraint (2).

Let $S\left(\rho_{n}, z_{n}\right)$ denote the flow of total social surplus generated by the current patent, consisting of the consumer surplus $C\left(\rho_{n}, z_{n}\right)$, the producer surplus $P\left(\rho_{n}, z_{n}\right)$, and the efficiency loss $\chi\left(\rho_{n}, z_{n}\right)$ associated with patent monopoly, i.e.23

$$
S\left(\rho_{n}, z_{n}\right) \equiv C\left(\rho_{n}, z_{n}\right)+P\left(\rho_{n}, z_{n}\right)+\chi\left(\rho_{n}, z_{n}\right)
$$

where

$$
P\left(\rho_{n}, z_{n}\right) \equiv \widehat{\pi}\left(\kappa\left(\rho_{n}, z_{n}\right), z_{n}\right)
$$

Functions $S, C$ and $P$ are assumed to be increasing in both arguments. In what follows, $\chi\left(\rho_{n}, z_{n}\right)$ is often referred to as the standard deadweight loss, but it could include other sources of monopoly inefficiency 24 If the current patent expires after $T$, the production market returns to competition and the full social surplus $S\left(\rho_{n}, z_{n}\right)$ is realized. If the current patent terminates because a new patent $z_{n+1}$ is filed before $T$ with protection $\rho_{n+1}$, the old deadweight loss $\chi\left(\rho_{n}, z_{n}\right)$ is replaced by a new deadweight loss $\chi\left(\rho_{n+1}, z_{n+1}\right)$, a result of the new monopoly.

We first formulate the continuation value for the planner at time $T$ when the current patent $z_{n}$ just expires. In this case, there is no promise for the planner to keep, and the relevant policy instruments are the cutoffs and reward functions. Let $V^{f}\left(\rho_{n}, z_{n}\right)$ denote the continuation value in the "free" state with no active patent, when the expired patent $z_{n}$ was awarded patent protection $\rho_{n}$. Then we can write $V^{f}\left(\rho_{n}, z_{n}\right)$ as

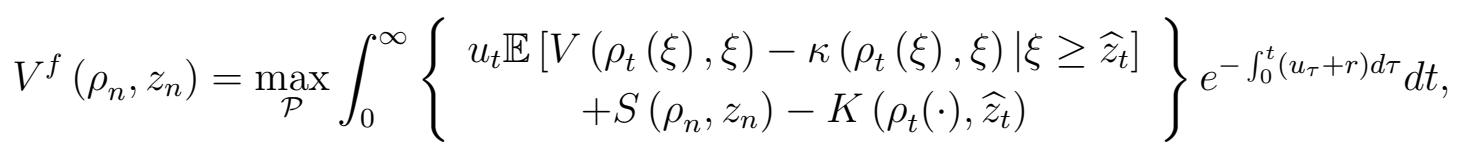

where $V\left(\rho_{t}(z), z\right)$ denotes the continuation value for the planner immediately after a new patent $z$ is approved with promised patent duration $\rho_{t}(z)$ and the development investment $\kappa\left(\rho_{t}(z), z\right)$ is made. Here $t$ denotes the calender time since the expiration of patent $z_{n}$. Note that the product prevailing in the current market is based on the expired patent $z_{n}$.

\footnotetext{
${ }^{23}$ The functional form of $S, C$ and $P$ may differ across different generations of technologies. Hence, we should index each function by $n$. To simplify notation, we suppress this index when no confusion arises, but the reader should keep this in mind.

${ }^{24}$ For example, it could include the efficiency loss due to poor management practice (Bloom and Van Reenen, 2007).
} 
To understand this formula, note that when no patentable idea arrives at time $t$, the planner collects the full social surplus $S\left(\rho_{n}, z_{n}\right)$ due to competitive pricing, and in the meantime she incurs a flow research cost of $K\left(\widehat{z}_{t}, \rho_{t}(\cdot)\right)$. When a new patentable idea $\xi \geq \widehat{z}_{t}$ arrives at time $t$, a continuation payoff $V\left(\rho_{t}(\xi), \xi\right)$ is received and a development investment $\kappa\left(\rho_{t}(\xi), \xi\right)$ is incurred. Finally, the arrival process of patentable ideas under $\mathcal{P}$ is a non-homogeneous Poisson process with arrival rate $u_{t}$ which is defined in (4).

It follows from the free-entry condition (3) that

$$
\lambda\left(\rho_{t}(\cdot), \widehat{z}_{t}\right) \int_{\widehat{z}_{t}}^{\infty} \pi\left(\rho_{t}(\xi), \xi\right) \phi(\xi) d \xi=K\left(\rho_{t}(\cdot), \widehat{z}_{t}\right)
$$

which is equivalent to

$$
u_{t} \mathbb{E}\left[\pi\left(\rho_{t}(\xi), \xi\right) \mid \xi \geq \widehat{z}_{t}\right]=K\left(\rho_{t}(\cdot), \widehat{z}_{t}\right)
$$

As argued in Posner (1975), the producer surplus or the rent captured by the monopolist should also be counted as part of the social cost of monopoly. In our model, the research cost incurred in order to obtain a patent is, on the margin, equal to the total producer surplus generated by the patent, as shown in the above rent-dissipation condition (6). However, different from monopoly model considered in Posner (1975), the incurred research cost here generates new ideas - a socially valuable by-product.

Therefore, we can rewrite $V^{f}\left(\rho_{n}, z_{n}\right)$ as

$$
V^{f}=\max _{\mathcal{P}} \int_{0}^{\infty}\left\{\begin{array}{c}
u_{t} \mathbb{E}\left[V\left(\rho_{t}(\xi), \xi\right)-\kappa\left(\rho_{t}(\xi), \xi\right)-\pi\left(\rho_{t}(\xi), \xi\right) \mid \xi \geq \widehat{z}_{t}\right] \\
+S\left(\rho_{n}, z_{n}\right)
\end{array}\right\} e^{-\int_{0}^{t}\left(u_{\tau}+r\right) d \tau} d t
$$

Intuitively, the conditional expectation term can be interpreted as the net expected surplus generated by a new patentable idea, which is the future benefit $(V)$ minus the development cost $(\kappa)$ and the accumulated research cost (which is translated into $\pi$ by the rent-dissipation condition (60)).

After we formulate the continuation value $V^{f}\left(\rho_{n}, z_{n}\right)$, we can write the planner's continuation value $V\left(\rho_{n}, z_{n}\right)$ as

$$
V\left(\rho_{n}, z_{n}\right)=\max _{\mathcal{P}}\left\{\begin{array}{c}
\int_{0}^{T}\left\{u_{t} \mathbb{E}\left[V\left(\rho_{t}(\xi), \xi\right)-\kappa\left(\rho_{t}(\xi), \xi\right) \mid \xi \geq \widehat{z}_{t}\right]\right\} e^{-\int_{0}^{t}\left(u_{\tau}+r\right) d \tau} d t \\
+\int_{0}^{T}\left[C\left(\rho_{n}, z_{n}\right)+P\left(\rho_{n}, z_{n}\right)-K\left(\rho_{t}(\cdot), \widehat{z}_{t}\right)\right] e^{-\int_{0}^{t}\left(u_{\tau}+r\right) d \tau} d t \\
+e^{-\int_{0}^{T}\left(u_{\tau}+r\right) d \tau} V^{f}\left(\rho_{n}, z_{n}\right)
\end{array}\right\} .
$$

To understand this formula, note that under policy $\mathcal{P}$, if an idea $z$ arrives at time $t<$ $T$ and $z \geq \widehat{z}_{t}$, the idea is patented and rewarded with patent duration $\rho_{t}(z)$. After incurring a lump-sum development cost $\kappa\left(\rho_{t}(z), z\right)$, the planner receives continuation payoff $V\left(\rho_{t}(z), z\right)$. During the inter-arrival period $[0, t]$, the planner collects the flow 
of consumer surplus and producer surplus $(C+P)$ generated by the current patent but she also incurs the flow aggregate research cost $K\left(\rho_{t}(\cdot), \widehat{z}_{t}\right)$. If no patentable idea arrives before $T$, which happens with probability $\exp \left(-\int_{0}^{T} u_{\tau} d \tau\right)$, the current patent expires and the planner gets continuation value $V^{f}\left(\rho_{n}, z_{n}\right)$. Using the free-entry condition (3), we can rewrite the planner's problem as

$$
\max _{\mathcal{P}}\left\{\begin{array}{c}
\int_{0}^{T} u_{t} \mathbb{E}\left[V\left(\rho_{t}(\xi), \xi\right)-\kappa\left(\rho_{t}(\xi), \xi\right)-\pi\left(\rho_{t}(\xi), \xi\right) \mid \xi \geq \widehat{z}_{t}\right] e^{-\int_{0}^{t}\left(u_{\tau}+r\right) d \tau} d t \\
+\int_{0}^{T}\left[C\left(\rho_{n}, z_{n}\right)+P\left(\rho_{n}, z_{n}\right)\right] e^{-\int_{0}^{t}\left(u_{\tau}+r\right) d \tau} d t+e^{-\int_{0}^{T}\left(u_{\tau}+r\right) d \tau} V^{f}\left(\rho_{n}, z_{n}\right)
\end{array}\right\} .
$$

As we discussed above, when choosing $\mathcal{P}$, the planner has to respect the promising-keeping constraint (2):

$$
\int_{0}^{T} e^{-\int_{0}^{s}\left(u_{\tau}+r\right) d \tau} d s=\rho_{n}
$$

\section{Optimal Policy with No Active Patent}

We first characterize the optimal patent policy in the "free" state with no active patent. Since there is no active patent, there is no expiration date and the patent policy $\mathcal{P}$ consists of a sequence of cutoffs $\left\{\widehat{z}_{t}\right\}_{t=0}^{\infty}$ and a sequence of reward functions $\left\{\rho_{t}(\cdot)\right\}_{t=0}^{\infty}$. To facilitate the analysis, let us define $Q\left(u_{t}, \rho_{t}(\cdot), \widehat{z}_{t}\right)$ as:

$$
Q\left(u_{t}, \rho_{t}(\cdot), \widehat{z}_{t}\right) \equiv u_{t} \mathbb{E}\left[V\left(\rho_{t}(\xi), \xi\right)-\kappa\left(\rho_{t}(\xi), \xi\right)-\pi\left(\rho_{t}(\xi), \xi\right) \mid \xi \geq \widehat{z}_{t}\right]
$$

With abuse of notation, we define

$$
Q\left(u_{t}\right) \equiv \max _{\left\{\rho_{t}(\cdot), \widehat{z}_{t}: \lambda\left(\rho_{t}(\cdot), \widehat{z}_{t}\right)\left[1-\Phi\left(\widehat{z}_{t}\right)\right]=u_{t}\right\}} Q\left(u_{t}, \rho_{t}(\cdot), \widehat{z}_{t}\right)
$$

Therefore, $Q\left(u_{t}\right)$ is the flow payoff that is translated from the expected net surplus associated with future innovation when patentable ideas arrive at rate $u_{t}$. Note that state variables $\rho_{n}$ and $z_{n}$ enter the $Q$ function only through $u_{t}$. We can rewrite the value function $V^{f}\left(\rho_{n}, z_{n}\right)$ as 25

$$
V^{f}\left(\rho_{n}, z_{n}\right)=\max _{\left\{u_{t}\right\}_{t=0}^{\infty}} \int_{0}^{\infty}\left[Q\left(u_{t}\right)+S\left(\rho_{n}, z_{n}\right)\right] e^{-\int_{0}^{t}\left(u_{\tau}+r\right) d \tau} d t .
$$

${ }^{25}$ The reformulation is based on the following observation:

$$
\begin{aligned}
& \max _{\left\{u_{t}, \rho_{t}(\cdot), \bar{z}_{t}\right\}_{t=0}^{\infty}} \int_{0}^{\infty}\left[Q\left(u_{t}, \rho_{t}(\cdot), \widehat{z}_{t}\right)+S\left(\rho_{n}, z_{n}\right)\right] e^{-\int_{0}^{t}\left(u_{\tau}+r\right) d \tau} d t \\
= & \max _{\left\{u_{t}\right\}_{t=0}^{\infty}} \int_{0}^{\infty}\left\{\max _{\left\{\rho_{t}(\cdot), \widehat{z}_{t}: \lambda\left(\rho_{t}(\cdot), \widehat{z}_{t}\right)\left[1-\Phi\left(\widehat{z}_{t}\right)\right]=u_{t}\right\}} Q\left(u_{t}, \rho_{t}(\cdot), \widehat{z}_{t}\right)+S\left(\rho_{n}, z_{n}\right)\right\} e^{-\int_{0}^{t}\left(u_{\tau}+r\right) d \tau} d t .
\end{aligned}
$$


Let $\bar{\lambda}$ denote the maximal arrival rate of ideas at time $t$ that can be possibly induced in equilibrium. Since $\widehat{z}_{t} \geq 0$ and $\rho_{t}(z) \leq 1 / r$ for all $z$, we must have

$$
\bar{\lambda}=\gamma\left(K_{\max }\right) K_{\max }
$$

where $K_{\max }$ is the unique solution to the equation (3) when $\widehat{z}_{t}=0$ and $\rho_{t}(z)=1 / r$ for all $z$, which is replicated here:

$$
\gamma\left(K_{\max }\right) \int_{0}^{\infty} \pi(1 / r, \xi) \phi(\xi) d \xi=1 .
$$

Let us define $u^{*}\left(\rho_{n}, z_{n}\right)$ as

$$
u^{*}\left(\rho_{n}, z_{n}\right)=\arg \max _{u \in[0, \bar{\lambda}]} \frac{Q(u)+S\left(\rho_{n}, z_{n}\right)}{u+r} .
$$

Note that the expression inside the arg max operator represents the continuation value generated by a constant arrival rate $u$ in the absence of an active patent. Hence, $u^{*}$ maximizes the continuation value among all constant arrival rates $u \in[0, \bar{\lambda}]$. If the maximizer is not unique, we pick the smallest one. The following proposition characterizes the optimal policy when there is no active patent.

Proposition 1 In the absence of active patents, a policy with $u_{t}=u^{*}\left(\rho_{n}, z_{n}\right)$ for all $t$ is optimal. The continuation payoff $V^{f}\left(\rho_{n}, z_{n}\right)$ is given by

$$
V^{f}\left(\rho_{n}, z_{n}\right)=\frac{Q\left(u^{*}\left(\rho_{n}, z_{n}\right)\right)+S\left(\rho_{n}, z_{n}\right)}{u^{*}\left(\rho_{n}, z_{n}\right)+r} .
$$

Intuitively, when there is no active patent, the environment is stationary up to the arrival of the next patentable idea, as is the optimal patent policy. Note that a higher arrival rate $u$ affects the continuation value through three channels. First, the expected waiting time for the next innovation is smaller, which increases the continuation value. Second, the patent breadth or quality cutoff is smaller so the expected quality of the next innovation is lower, which decreases the continuation value. Third, the planner has a shorter time span to collect the social surplus $S\left(\rho_{n}, z_{n}\right)$ generated by the current (expired) patent $z_{n}$, which also hurts the continuation value. The optimal arrival rate of patentable ideas is constant and chosen appropriately to balance these three possible effects.

To conclude this section, we argue that $u^{*}\left(\rho_{n}, z_{n}\right)$ is interior and thus must satisfy the first-order condition for problem 11 . By definition, $u^{*}\left(\rho_{n}, z_{n}\right) \in[0, \lambda]$. If $u^{*}\left(\rho_{n}, z_{n}\right)=0$, innovation stops. If $u^{*}\left(\rho_{n}, z_{n}\right)=\overline{\bar{\lambda}}$, the planner must set $\rho_{t}(z)=1 / r$ for all $z$ and $t$. As a result, once an idea arrives and a new patent is filed and commercialized, innovation again 
stops. Neither case is realistic or interesting. Therefore, we assume $u^{*}\left(\rho_{n}, z_{n}\right) \in(0, \bar{\lambda})$ for all $\left(\rho_{n}, z_{n}\right)$. By the definition of $u^{*}\left(\rho_{n}, z_{n}\right)$ and Proposition 1 , we must have

$$
Q^{\prime}\left(u^{*}\left(\rho_{n}, z_{n}\right)\right)=V^{f}\left(\rho_{n}, z_{n}\right)
$$

To ease notation, we will suppress the dependence of $u^{*}$ on $\left(\rho_{n}, z_{n}\right)$ when no confusion will arise.

\section{Optimal Policy with Active Patent}

This section will characterize the optimal patent policy when there is an active patent $z_{n}$ with a promised patent duration $\rho_{n}$. Using the notation $Q\left(u_{t}\right)$, we can rewrite the planner's optimization problem as

$$
V\left(\rho_{n}, z_{n}\right)=\max _{T,\left\{u_{t}\right\}_{t=0}^{\infty}}\left\{\begin{array}{c}
\int_{0}^{T}\left[Q\left(u_{t}\right)+C\left(\rho_{n}, z_{n}\right)+P\left(\rho_{n}, z_{n}\right)\right] e^{-\int_{0}^{t}\left(u_{\tau}+r\right) d \tau} d t \\
+V^{f}\left(\rho_{n}, z_{n}\right) e^{-\int_{0}^{T}\left(u_{\tau}+r\right) d \tau}
\end{array}\right\}
$$

subject to the promise-keeping constraint (2).

\subsection{Reformulation of the Planner's Problem}

We first reformulate the planner's problem into a standard optimal control problem by a sequence of changes of variables. Let's define state variable $x(t)$ as

$$
x(t)=e^{-\int_{0}^{t}[u(\tau)+r] d \tau}
$$

with boundary conditions $x_{0}=1$ and $x_{T}$ free. Then we have

$$
\dot{x}(t)=-[u(t)+r] x(t),
$$

which implies that

$$
x(T)=1-\int_{0}^{T}[u(t)+r] x(t) d t .
$$

Let us introduce another state variable $y(t)$ which is defined as

$$
y(t)=\int_{0}^{t} x(s) d s
$$

Then we can replace the promise-keeping constraint (2) by

$$
\dot{y}(t)=x(t) \text { with boundary condition } y_{0}=0 \text { and } y_{T}=\rho_{n} \text {. }
$$


Let $u(t)$ be the control variable and $(x(t), y(t))$ be the state variables. We use expression (16) to rewrite the planner's problem as

$$
\begin{aligned}
& \max _{T, u(t)} \int_{0}^{T}\left[Q(u(t))+C+P-(u(t)+r) V^{f}\right] x(t) d t+V^{f} \\
\text { subject to }: & \dot{x}(t)=-[u(t)+r] x(t) \\
: & \dot{y}(t)=x(t) \\
: & x_{0}=1 \text { and } x_{T} \text { free } \\
: & y_{0}=0 \text { and } y_{T}=\rho_{n} \\
: & u(t) \in U \equiv\{u: 0 \leq u \leq \bar{\lambda}\}
\end{aligned}
$$

From now on, we will refer to this concave optimal control problem as Program $\mathcal{C}$. Mathematically, it is an optimal control problem with free terminal time.

\subsection{Optimal Structuring of Given Reward}

We assume for now that the function $Q(u)$ is strictly concave in $u$, which will be relaxed in Section 4.4. The Hamiltonian is given by

$$
\begin{aligned}
H\left(x, y, u, p_{1 T}, p_{2 T}, t\right)= & {\left[Q(u(t))+C+P-(u(t)+r) V^{f}\right] x(t) } \\
& -p_{1 T}(t)[u(t)+r] x(t)+p_{2 T}(t) x(t),
\end{aligned}
$$

where $p_{1 T}(t)$ and $p_{2 T}(t)$ are the adjoint functions associated with (19) and (20), respectively. Define $\widehat{H}\left(x, y, p_{1 T}, p_{2 T}, t\right)$ as the maximum value of the Hamiltonian when $u$ is chosen optimally:

$$
\widehat{H}\left(x, y, p_{1 T}, p_{2 T}, t\right) \equiv \max _{u} H\left(x, y, u, p_{1 T}, p_{2 T}, t\right)
$$

Let $u_{T}(t)$ denote the optimal control that solves Program $\mathcal{C}$, and let $x_{T}(t)$ and $y_{T}(t)$ denote the associated optimal path.

To facilitate the analysis, we introduce two more notations: $u_{n}$ and $T^{*}$. First, we define $u_{n}$ as

$$
\rho_{n}=\int_{0}^{\infty} e^{-\int_{0}^{s}\left(u_{n}+r\right) d \tau} d s=\frac{1}{u_{n}+r} .
$$

That is, a patent policy with $u_{t}=u_{n}$ for all $t$ delivers patent duration $\rho_{n}$. Next, we define $T^{*}$ as the solution to the following equation:

$$
\rho_{n}=\left(1-e^{-\left(u^{*}+r\right) T^{*}}\right) /\left(u^{*}+r\right)
$$

That is, a patent policy with $T=T^{*}$ and $u_{t}=u^{*}$ for all $t \leq T^{*}$ delivers patent duration $\rho_{n}$. Note that $T^{*}$ is finite if and only if $u^{*}<u_{n}$. 
We first consider the infinite horizon case where $T$ is exogenously fixed at $\infty$. In this case, the optimal policy is simple: set a constant cutoff through time such that the patent duration $\rho_{n}$ is delivered.

Proposition 2 (Concave $Q$, Infinite Horizon) Suppose $Q$ is strictly concave. The optimal solution to Program $\mathcal{C}$ with $T=\infty$ is $u_{\infty}(t)=u_{n}$ for all $t$, and

$$
V^{\infty}\left(\rho_{n}, z_{n}\right)=\rho_{n}\left[Q\left(u_{n}\right)+C\left(\rho_{n}, z_{n}\right)+P\left(\rho_{n}, z_{n}\right)\right]
$$

In the prior literature, much attention has been paid to settings where the idea arrival process is exogenous (e.g., OST and HLM). For comparison, suppose innovation ideas occur randomly and freely to individual research firms, and the aggregate arrival rate $\lambda$ of new ideas is exogenously fixed. We can characterize the optimal policy with exogenous arrival of ideas as a corollary of Proposition 2 , by showing that $Q$ is necessarily concave if the idea arrival process is exogenous. It replicates the characterization of optimal policy in HLM where the idea arrival process is assumed to be deterministic and exogenous.

Corollary 1 Suppose the arrival process of new ideas is exogenous with arrival rate $\lambda$. Further assume that the patent length is fixed at infinity (i.e., $T=\infty)$. Then $Q(u)$ is concave in $u$. Therefore, the optimal policy sets $u(t)=u_{n}$ for all $t$.

Next we consider our main interest, the case where $T$ is optimally chosen and is finite. Given the concavity of $Q$ and the characterization of optimal policy in Proposition 1, we conjecture that the optimal solution $u_{T}(t)=u^{*}$ for all $t$ while the optimal patent length $T^{*}$ is implicitly defined in (27). To verify this solution, we apply the following sufficiency theorem with free terminal time.

Consider Program $\mathcal{C}$ with free terminal time $T \in[0, \widehat{T}]$, where $\widehat{T}$ is finite but can be arbitrarily large. Suppose for each $T \in[0, \widehat{T}]$, there exists a vector $\left(x_{T}(t), y_{T}(t), u_{T}(t)\right.$, $\left.p_{1}(t), p_{2}(t)\right)$ defined on $[0, \widehat{T}]$ satisfying the conditions in Arrow's sufficiency theorem with finite horizon. If $x_{T}(T)$ is continuous in $T$, the set $\left\{p_{1 T}, p_{2 T}: T \in[0, \widehat{T}]\right\}$ is bounded, and the function

$$
F(T) \equiv H\left(x_{T}(T), y_{T}(T), u_{T}(T), p_{1 T}(T), p_{2 T}(T), T\right)
$$

has the property that there exists a $T^{*} \in[0, \widehat{T}]$ such that

$$
\begin{gathered}
F\left(T^{*}\right)=0 \\
F(T) \geq 0 \text { for all } T \leq T^{*}, \\
F(T) \leq 0 \text { for all } T \geq T^{*}
\end{gathered}
$$

then $\left(x_{T^{*}}(t), y_{T^{*}}(t), u_{T^{*}}(t)\right)$ defined on $\left[0, T^{*}\right]$ solves Program $\mathcal{C}$ with free terminal time $T{ }^{26}$ Applying this theorem, we obtain the following characterization.

\footnotetext{
${ }^{26}$ Theorem 13 in Seierstad and Sydsaeter (1987), page 145. This sufficiency theorem is similar to
} 
Proposition 3 (Concave Q, Endogenous T) Suppose $Q$ is strictly concave and $T^{*}$ is finite. The optimal solution to Program $\mathcal{C}$ with free terminal time $T \in[0, \widehat{T}]$ is $T=T^{*}$ and $u_{T^{*}}(t)=u^{*}$ for all $t$. Moreover,

$$
V\left(\rho_{n}, z_{n}\right)=V^{f}\left(\rho_{n}, z_{n}\right)-\chi\left(\rho_{n}, z_{n}\right) \rho_{n} .
$$

The proof in the Appendix proceeds in two steps. The first step applies Arrow's sufficiency theorem with finite horizon to characterize the optimal patent policy with finite and exogenous $T$, establishing the existence of the vector $\left(x_{T}(t), y_{T}(t), u_{T}(t)\right.$, $\left.p_{1}(t), p_{2}(t)\right)$ that satisfies the conditions in Arrow's sufficiency theorem. Building on this characterization, the second step shows that the shadow price of the promise-keeping constraint, $\bar{p}_{2 T}$, is equal to the flow deadweight loss $\chi\left(\rho_{n}, z_{n}\right)$ if and only if $T=T^{*}$. Specifically,

$$
\begin{array}{ll}
\bar{p}_{2 T}<\chi\left(\rho_{n}, z_{n}\right) & \text { if } T>T^{*} \\
\bar{p}_{2 T}=\chi\left(\rho_{n}, z_{n}\right) & \text { if } T=T^{*} . \\
\bar{p}_{2 T}>\chi\left(\rho_{n}, z_{n}\right) & \text { if } T<T^{*}
\end{array}
$$

This property is then used to verify condition (29).

To gather some intuition about the relationship (30), we insert the optimal solution with finite $T^{*}$ back into the objective function to obtain

$$
V\left(\rho_{n}, z_{n}\right)=\left[Q\left(u^{*}\right)+C\left(\rho_{n}, z_{n}\right)+P\left(\rho_{n}, z_{n}\right)\right] \rho_{n}+e^{-\left(u^{*}+r\right) T^{*}} V^{f}\left(\rho_{n}, z_{n}\right)
$$

Using the relation between $\rho_{n}$ and $u^{*}$ in 27) and the expression of $V^{f}$ in 12), we can reduce the above expression for $V$ to $(30)$. Intuitively, the continuation value $V\left(\rho_{n}, z_{n}\right)$ with an active patent equals the continuation value with no active patent $V^{f}\left(\rho_{n}, z_{n}\right)$ minus the deadweight loss cumulated during the period that the patent is valid.

An alternative perspective to understand the relationship (30) between $V$ and $V^{f}$ is to compare the two maximization problems. They share the same objective function, but the maximization problem for $V$ has to respect the promise-keeping constraint (2) while the maximization problem for $V^{f}$ is unconstrained. Since the shadow price $\bar{p}_{2 T}$ of the promise-keeping constraint when $T=T^{*}$ equals the deadweight loss $\chi\left(\rho_{n}, z_{n}\right)$, the social cost of maintaining the constraint is $\chi\left(\rho_{n}, z_{n}\right) \rho_{n}$. Hence, the relationship (30) is expected: $V$ should differ from $V^{f}$ by $\chi\left(\rho_{n}, z_{n}\right) \rho_{n}$.

This alternative perspective also provides intuition why the optimal solution $u_{T^{*}}(t)=$ $u^{*}$ for all $t$. Because $Q$ is concave, the optimal control is constant before $T^{*}$ and after

Arrow's sufficiency theorem with finite horizon. But with free terminal time, we need the additional condition (29). Seierstad (1984) observes that $F(T)$ is the optimal value of Program $C$ as a function of the terminal time $T$, and condition $(29)$ is sufficient for the optimal value $F(T)$ to be maximized at $T=T^{*}$. 
$T^{*}$, but there is no a priori reason that $u_{T^{*}}(t)$ should not jump at $t=T^{*}$ when the current patent expires. However, since the optimal value of the planner's maximization problem before $T^{*}$ and after $T^{*}$ differs only by a constant $\chi\left(\rho_{n}, z_{n}\right) \rho_{n}$ for given $\left(\rho_{n}, z_{n}\right)$, the planner must face the same tradeoff before and after $T^{*}$. It follows that the optimal arrival rate of patentable ideas $u_{T^{*}}(t)$ should not jump at $t=T^{*}$.

Proposition 3 has an important implication: for a given patent reward, a better patent with higher social surplus should be broader but expire sooner. To see this, note that the optimal solution $u^{*}$ is implicitly defined in (13):

$$
Q^{\prime}\left(u^{*}\right)=V^{f}\left(\rho_{n}, z_{n}\right)=\frac{Q\left(u^{*}\right)+S\left(\rho_{n}, z_{n}\right)}{u^{*}+r}
$$

which implies that

$$
Q^{\prime}\left(u^{*}\right)\left(u^{*}+r\right)-Q\left(u^{*}\right)=S\left(\rho_{n}, z_{n}\right)
$$

By concavity of $Q, Q^{\prime}\left(u^{*}\right)\left(u^{*}+r\right)-Q\left(u^{*}\right)$ is decreasing in $u^{*}$, so $u^{*}$ is decreasing in the size of total surplus $S\left(\rho_{n}, z_{n}\right)$. That is, a patent that generates a higher social surplus should correspond to a smaller $u^{*}$. Further recall (9) that $u^{*}$ relates to the reward function $\rho_{t}(\cdot)$ and patent breadth $\widehat{z}_{t}$ through the following constrained maximization problem:

$$
\begin{array}{cc}
\max _{\rho_{t}(\cdot), \widehat{z}_{t}} Q\left(u^{*}, \rho_{t}(\cdot), \widehat{z}_{t}\right) \\
\text { subject to }: \quad \lambda\left(\rho_{t}(\cdot), \widehat{z}_{t}\right)\left[1-\Phi\left(\widehat{z}_{t}\right)\right]=u^{*}
\end{array}
$$

Since $u^{*}$ is independent of $t$, the above maximization problem is time-invariant. As a result, the optimal solution $\rho_{t}(\cdot)$ and $\widehat{z}_{t}$ must be independent of $t$, and we can write $\rho(\cdot)$ and $\widehat{z}$, respectively. Moreover, the patent breadth $\widehat{z}$ is decreasing in $u^{*}$. Therefore, one should reward an innovation of higher social surplus $S\left(\rho_{n}, z_{n}\right)$ by a broader but shorter patent.

The intuition for the tradeoff between patent length and breadth is as follows. For the case with no active patent, the product market is fully competitive and there is no efficiency loss. As we pointed out earlier, the planner faces the tradeoff between having a new innovation sooner or having a better innovation. When the planner is waiting for the next innovation, she is also collecting the social surplus, $S\left(\rho_{n}, z_{n}\right)$, generated by the current (expired) patent. Therefore, the larger the social surplus, the smaller the waiting cost, and the more selective the planner's choice of patentable innovation, which implies a higher optimal cutoff $\widehat{z}$. As a result, there is a replacement effect from the planner's perspective, akin to the standard Arrow's replacement effect from the incumbent firm's perspective. Since the social cost to maintain the promise-keeping constraint is constant for a given reward, the above cutoff $\widehat{z}$ is also optimal for the setting with an active patent.

To complete the characterization of the socially optimal mix of patent length and breadth for a given reward, we need to compare social welfare under optimal policy with 
$T<\infty$ with social welfare under optimal policy with $T=\infty$. Note that we cannot directly apply the above sufficiency theorem with free terminal time by allowing $\widehat{T}$ to take $\infty$, i.e., $\widehat{T} \in(0, \infty) \cup\{\infty\}$, because the theorem requires that $u_{T}(T)$ is continuous in $T$ for all $T \in[0, \widehat{T}]$ but $u_{T}(T)$ is not continuous in the limit $T=\infty$ as long as $u^{*} \neq u_{n}$. To see this, note that the boundary condition $u_{T}(T)=u^{*}$, condition (48) in the Appendix, for the optimal control with finite $T$ does not depend on $T$. But with $T=\infty$, we have $u_{\infty}(t)=u_{n}$ for all $t$. Therefore, $\lim _{T \rightarrow \infty} u_{T}(T) \neq u_{\infty}(\infty)$ as long as $u^{*} \neq u_{n}$.

Proposition 4 (Optimal Policy, Concave Q) If $u^{*}\left(\rho_{n}, z_{n}\right)<u_{n}$, then the optimal policy sets $T=T^{*}\left(\rho_{n}, z_{n}\right)$ and $u(t)=u^{*}\left(\rho_{n}, z_{n}\right)$ for all $t$. If $u^{*}\left(\rho_{n}, z_{n}\right) \geq u_{n}$, then the optimal policy sets $T=\infty$ and $u(t)=u_{n}$ for all $t$.

Therefore, for a given reward size $\rho_{n}$, if the social surplus $S\left(\rho_{n}, z_{n}\right)$ associated with patent $z_{n}$ is high, patent $z_{n}$ will have a finite patent length but enjoy broader protection. On the other hand, if patent $z_{n}$ generates a low social surplus $S\left(\rho_{n}, z_{n}\right)$, it will have an infinite patent length but enjoy narrower protection.

Finally, we would like to point out that the radical innovation assumption is not critical for the above analysis. If innovation is not radical, so that the pricing of a new product is constrained by the competition from an existing product, then the price of the new product based on the $n$-th patent may depend on the $(n-1)$-th patent. The equilibrium price will not affect the social surplus $S\left(\rho_{n}, z_{n}\right)$ generated by the $n$-th patent but will affect its decomposition. That is, consumer surplus $C$, producer surplus $P$ and deadweight loss $\chi$ will be functions not only of $\rho_{n}$ and $z_{n}$, but also of $\rho_{n-1}$ and $z_{n-1}$. As a result, $\rho_{n-1}, z_{n-1}, \rho_{n}$, and $z_{n}$ will directly enter the function $Q$. With non-radical innovation, condition (32) for $u^{*}$ becomes

$$
Q^{\prime}\left(u^{*} ; \rho_{n-1}, z_{n-1}, \rho_{n}, z_{n}\right)\left(u^{*}+r\right)-Q\left(u^{*} ; \rho_{n-1}, z_{n-1}, \rho_{n}, z_{n}\right)=S\left(\rho_{n}, z_{n}\right) .
$$

Therefore, the analysis of non-radical innovation will be qualitatively similar to the case of radical innovation. In Section 5, we demonstrate how to adapt our analysis to a special setting with incremental innovation.

\subsection{Optimal Reward Size: Higher Deadweight Loss, Smaller Re- ward}

Thus far we have characterized the optimal mix of patent length and breadth to deliver a given reward size. Most of the literature on patent design stops here, for example, Gilbert and Shapiro (1990) and Klemperer (1990). Another important question of patent design left answered is how much to reward each innovation. As pointed out by Gilbert 
and Shapiro (1990), to derive optimal reward size, one needs additional knowledge about the demand and supply conditions for innovation. Moreover, this question is also less tractable. Hence, we content ourselves here by delineating factors that are important in determining the optimal reward size. In particular, we demonstrate how the decomposition of social surplus, the fraction of social surplus being the deadweight loss, affects the reward size.

To gain insight into this question, we relate the optimal control solution $u(t)$ to the two patent instruments: patent reward function $\rho(\cdot)$ and patent breadth $\widehat{z}$. To ease exposition, we again assume that $Q$ is concave, and focus on the case where the optimal patent length $T^{*}$ is finite.

Recall from (33) that $\rho(\cdot)$ and $\widehat{z}$ solve the following constrained maximization problem:

$$
\begin{array}{ll} 
& \max _{\rho(\cdot), \widehat{z}} Q\left(u^{*}, \rho(\cdot), \widehat{z}\right) \\
\text { subject to }: & \lambda(\rho(\cdot), \widehat{z})[1-\Phi(\widehat{z})]=u^{*}
\end{array}
$$

where $Q\left(u^{*}, \rho(\cdot), \widehat{z}\right)$ is defined by (8). Given our earlier characterization of $u^{*}$ and $V$, the functional form of $Q$ can, in principle, be derived from our primitives. Using constraint (34), we can write the cutoff $\widehat{z}$ as a function of the reward function $\rho(\cdot)$. By substituting $\widehat{z}\left(\rho(\cdot), u^{*}\right)$ into the objective, we can rewrite the optimization problem as

$$
\max _{\rho(\cdot)} Q\left(u^{*}, \rho(\cdot), \widehat{z}\left(\rho(\cdot), u^{*}\right)\right) .
$$

Let $N_{\epsilon}\left(z_{0}\right)$ denote a small interval $\left[z_{0}-\epsilon, z_{0}+\epsilon\right]$ around $z_{0}$ with $z_{0}-\epsilon>\widehat{z}$. If $\rho(z)$ increases uniformly for all $z \in N_{\epsilon}\left(z_{0}\right)$ while keeping $\rho(z)$ fixed for all $z \notin N_{\epsilon}\left(z_{0}\right)$, then $\widehat{z}\left(\rho(\cdot), u^{*}\right)$ increases ${ }^{27}$ Intuitively, as the reward for future ideas increases, the planner can strengthen the patentability requirement and still maintain the same arrival rate of the patentable ideas $u^{*}$. With small $\epsilon$, the marginal gain due to an increase of $\rho(z)$ uniformly for $z \in N_{\epsilon}\left(z_{0}\right)$ can be approximated by

$$
\begin{aligned}
& u^{*}\left\{\frac{\partial}{\partial \widehat{z}} \mathbb{E}\left[V\left(\rho_{t}(\xi), \xi\right)-\kappa\left(\rho_{t}(\xi), \xi\right)-\pi\left(\rho_{t}(\xi), \xi\right) \mid \xi \geq \widehat{z}_{t}\right]\right\} \frac{\partial \widehat{z}}{\partial[\rho(z)]_{z \in N_{\epsilon}\left(z_{0}\right)}} \\
& +\frac{u^{*}}{1-\Phi(\widehat{z})}\left(2 \phi\left(z_{0}\right) \epsilon\right)\left[V_{\rho}(\rho(z), z)-\kappa_{\rho}(\rho(z), z)-\pi_{\rho}(\rho(z), z)\right]
\end{aligned}
$$

The first line represents the indirect effect by raising the patent breadth $\widehat{z}$, while the second line captures the direct effect. With some algebra (details in the Appendix), we can rewrite $V_{\rho}(\rho, z)-\kappa_{\rho}(\rho, z)-\pi_{\rho}(\rho, z)$ as

$$
\rho C_{\rho}(\rho, z)-\chi(\rho, z)+\left(\frac{1}{u^{*}(\rho, z)+r}-\rho\right) S_{\rho}(\rho, z)-P(\rho, z) .
$$

\footnotetext{
${ }^{27}$ By considering an increase in patent reward for a small set of $z$ instead of a particular $z$, we ensure that the indirect effect through the patent breadth $\widehat{z}$ is well-defined.
} 
The four terms in (35) capture four different sources of the direct effect. The first term, $\rho C_{\rho}(\rho, z)$, is the positive externality on consumer surplus in the duration of the patent. A bigger reward encourages the patentee to invest more to develop his idea into a better product, generating higher consumer surplus in the patent duration $\rho$. But an increase in $\rho$ also increases the duration of the deadweight loss $\chi(\rho, z)$, which is the second term. To understand the third term, note that, after the patent terminates but before the next new patent is filed, consumers enjoy the total social surplus $S$. The expected waiting time for the next new innovation is $1 /\left[u^{*}(\rho, z)+r\right]-\rho$, which is positive if $T^{*}<\infty$ and vanishes if $T^{*}=\infty \sqrt{28}$ Therefore, the third term captures the accrued welfare gain during this waiting period. Finally, an increase in $\rho$ implies that the incumbent collects producer surplus, $P(\rho, z)$, for a longer period, which counts as a welfare cost because producer surplus is fully dissipated through competition in research.

To conclude this subsection, we investigate how the decomposition of the social surplus $(C+P+\chi)$ affects the optimal reward size. Suppose, for all $\rho$ and $z \in N_{\epsilon}\left(z_{0}\right), \chi(\rho, z)$ is shifted up by $\varepsilon>0$, and $C(\rho, z)$ is shifted down correspondingly by $\varepsilon$, while leaving both the producer surplus and the social surplus unchanged.29

Consider first the indirect effect of such a shift. Since the shift does not involve the producer surplus, the incentives of research firms remain unchanged. As a result, it does not affect the free-entry condition (3) which determines the aggregate flow of research investment $K(\rho(\cdot), \widehat{z})$ which will be the same before and after the shift. Furthermore, since $\widehat{z}$ and $\rho(\cdot)$ are linked by

$$
\lambda(K(\rho(\cdot), \widehat{z}))[1-\Phi(\widehat{z})]=u^{*}
$$

the function $\widehat{z}\left(\rho(\cdot), u^{*}\right)$ is also not affected by such a shift. Note further that $V(\rho, z)=$ $V^{f}(\rho, z)-\rho \chi(\rho, z)$ and $V^{f}$ is not affected by such a shift, so $V(\rho, z)$ is shifted down by $\rho \varepsilon$. Therefore, the indirect gain due to an increase in $\rho$ is smaller after the shift.

Next consider the direct effect. It is easy to see from (35) that the direct gain is also smaller when $\chi(\rho, z)$ is shifted up by $\varepsilon>0$. Hence, both direct and indirect effects go in the same direction, which implies that an increase in the proportion of deadweight loss in the total social surplus leads to a lower optimal reward. Therefore, the decomposition of the total social surplus does not play a role in structuring a given reward, but it is crucial in determining the size of the optimal reward.

\footnotetext{
${ }^{28}$ Note the reward $\rho$ is linked to $u^{*}$ and $T^{*}$ by $(27)$ with $\rho=\left(1-e^{-\left(u^{*}+r\right) T^{*}}\right) /\left(u^{*}+r\right)$.

${ }^{29}$ It may be due to, for instance, an decrease in the demand elasticity.
} 


\subsection{Generalize to Nonconcave $Q$}

So far we have assumed that the $Q$ function is strictly concave. If $Q$ is weakly concave, we lose uniqueness but our previous analysis still works. If $Q$ is not concave, we develop a technique below, which we call convex envelope approach, to generalize our previous analysis. We first form a concave function $\bar{Q}(u)$ from the original $Q(u)$ by replacing all its non-concave segments by corresponding linear segments as illustrated in Figure 2. We refer to $\bar{Q}(u)$ as the convex envelope of the original function $Q(u)$.

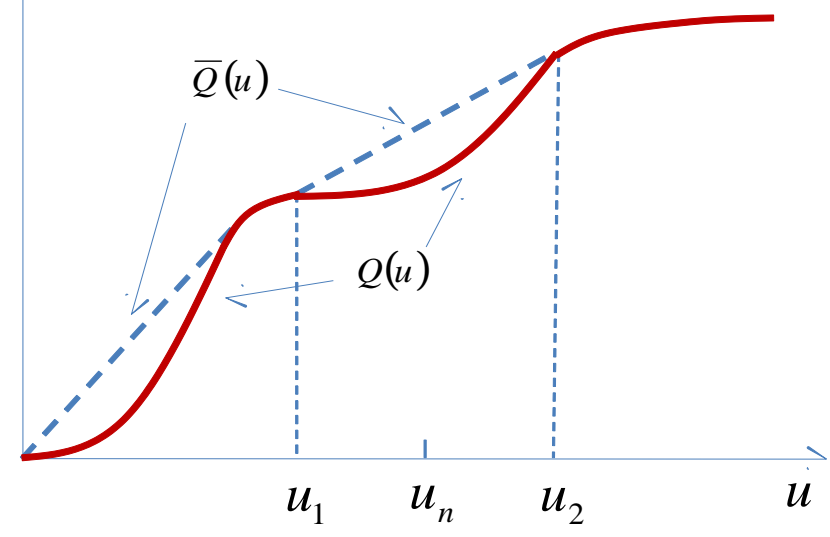

Figure 2: Convex envelope

Recall that the value function $V\left(\rho_{n}, z_{n}\right)$ is given by:

$$
V\left(\rho_{n}, z_{n}\right)=\max _{\left\{u_{t}\right\}_{t=0}^{\infty}}\left\{\int_{0}^{T}\left[Q\left(u_{t}\right)+C+P\right] e^{-\int_{0}^{t}\left(u_{\tau}+r\right) d \tau} d t+V^{f}\left(\rho_{n}, z_{n}\right) e^{-\int_{0}^{T}\left(u_{\tau}+r\right) d \tau}\right\}
$$

subject to the promise-keeping constraint (2). We define a new value function $\bar{V}\left(\rho_{n}, z_{n}\right)$, by replacing $Q$ function by its convex envelope $\bar{Q}$, as follows:

$$
\bar{V}\left(\rho_{n}, z_{n}\right)=\max _{\left\{u_{t}\right\}_{t=0}^{\infty}}\left\{\int_{0}^{T}\left[\bar{Q}\left(u_{t}\right)+C+P\right] e^{-\int_{0}^{t}\left(u_{\tau}+r\right) d \tau} d t+V^{f}\left(\rho_{n}, z_{n}\right) e^{-\int_{0}^{T}\left(u_{\tau}+r\right) d \tau}\right\}
$$

subject to the same promise-keeping constraint. By the definition of $\bar{Q}(u)$, it is clear that the optimal value $\bar{V}\left(\rho_{n}, z_{n}\right)$ achieved with the convex envelope $\bar{Q}(u)$ is weakly higher than the optimal value $V\left(\rho_{n}, z_{n}\right)$ achieved with the original function $Q(u)$. The next proposition shows that, in fact, $\bar{V}\left(\rho_{n}, z_{n}\right)=V\left(\rho_{n}, z_{n}\right)$.

Let $u^{*}$ and $T^{*}$ be the arrival rate and expiration time defined with respect to the convex envelope $\bar{Q}(u)$. Since $u^{*}$ is defined as the smallest $u$ that maximizes $(\bar{Q}(u)+S) /(u+r)$, $u^{*}$ cannot lie in the interior of a linear segment. Therefore, we must have $Q\left(u^{*}\right)=\bar{Q}\left(u^{*}\right)$. 
Proposition 5 (Optimal Policy, General Q) Suppose $Q$ is not concave. Then $\bar{V}\left(\rho_{n}, z_{n}\right)=$ $V\left(\rho_{n}, z_{n}\right)$. Furthermore, the optimal policy is described as follows:

(1) Finite horizon $\left(T^{*}<\infty\right)$. The optimal policy sets $T=T^{*}$ and $u(t)=u^{*}$ for all $t$.

(2) Infinite horizon $\left(T^{*}=\infty\right)$. If $Q\left(u_{n}\right)=\bar{Q}\left(u_{n}\right)$, the optimal policy sets $u(t)=u_{n}$ for all t. If $Q\left(u_{n}\right) \neq \bar{Q}\left(u_{n}\right)$, then $u_{n}$ must lie on some linear segment of $\bar{Q}$ with end points $\bar{Q}\left(u_{1}\right)$ and $\bar{Q}\left(u_{2}\right)$ and $u_{1}<u_{n}<u_{2}$. The optimal policy sets $u(t)=u_{1}$ if $t \leq \tau$ and $u(t)=u_{2}$ if $t>\tau$, where the transition time $\tau$ is chosen to keep the promise $\rho_{n}$ :

$$
\rho_{n}=\left(1-e^{-\left(u_{1}+r\right) \tau}\right) \frac{1}{u_{1}+r}+e^{-\left(u_{1}+r\right) \tau} \frac{1}{u_{2}+r} .
$$

The characterization of the optimal policy with general $Q$ function proceeds as follows. We first construct the convex envelope $\bar{Q}$, and apply Proposition 4 to the convex envelope $\bar{Q}$ to obtain $\bar{V}\left(\rho_{n}, z_{n}\right)$. Proposition 4 will also tell us whether optimal patents under $\bar{Q}$ will have finite patent length. We then show that the optimal value $\bar{V}\left(\rho_{n}, z_{n}\right)$ can be achieved under the original function $Q$ by choosing patent length $T$ and control $u(t)$ appropriately.

Specifically, if optimal patents under $\bar{Q}$ have finite patent length, then the optimal policy under $\bar{Q}$ and the optimal policy under $Q$ coincide. Otherwise, the optimal patents under $Q$ will have infinite patent length. In the latter case, if $u_{n}$ lies on a linear segment of $\bar{Q}$ (see Figure 2), the optimal policy under $Q$ is a "two-point" policy $\left(u_{1}, u_{2}, \tau\right)$, where $\bar{Q}\left(u_{1}\right)$ and $\bar{Q}\left(u_{2}\right)$ are the two end points of the linear segment that $\bar{Q}\left(u_{n}\right)$ lies on, with $u_{1}<u_{n}<u_{2}$. The transition time $\tau$ is chosen such that the promise keeping constraint is satisfied. If $u_{n}$ does not lie on a linear segment of $\bar{Q}$, then the optimal policy is $u(t)=u_{n}$ for all $t$.

\section{Incremental Innovation}

In this section, we assume that innovation is incremental so that the pricing of the new technology is constrained by the old technology. We will sketch below how our previous analysis can be adapted to this setting. To keep our exposition simple, we adopt the simple setting studied in HLM, except that the idea generation process here is endogenous and stochastic. We focus on the class of patent policies where the current patent expires immediately after a new patent is filed.

There is a mass of one consumers, and their demand is completely inelastic. A new product supersedes the old one by posting an incremental quality improvement $\Delta(\kappa, z)$, which is increasing in both development investment $\kappa$ and idea quality $z$. The pricing of the new product is constrained by the old technology, so the new product is sold at price $p=\Delta$. There is no cost associated with production in additional to the development cost. 
Consider the patentee of the $n$-th innovation $z_{n}$ which is promised a patent duration $\rho_{n}$. Its expected profits are given by

$$
\pi\left(z_{n}, \rho_{n}\right)=\max _{\kappa}\left[\Delta\left(\kappa, z_{n}\right) \rho_{n}-\kappa\right]
$$

Both equilibrium development investment $\kappa\left(\rho_{n}, z_{n}\right)$ and quality improvement $\Delta\left(\rho_{n}, z_{n}\right)$ will be functions of the promised patent duration $\rho_{n}$ and the idea quality $z_{n}$. The research process is the same as before, and the research investment at time $t$ is characterized by the same free-entry condition (3).

Consider the social welfare generated by the $n$-th innovation $z_{n}$, discounted to the point of time when the patent is filed. Given patent duration $\rho_{n}$ and idea quality $z_{n}$, the producer surplus is $\rho_{n} \Delta\left(\rho_{n}, z_{n}\right)$, and the consumer surplus is $\left(1 / r-\rho_{n}\right) \Delta\left(\rho_{n}, z_{n}\right)$. Therefore, the aggregate flow of consumer surplus and producer surplus is given by $\Delta\left(\rho_{n}, z_{n}\right)$. Since consumer demand is completely inelastic, there is no deadweight loss: $\chi\left(\rho_{n}, z_{n}\right)=0$.

As before, we can define the $Q$ function as in (8) and (9), and formulate the continuation value $V^{f}$ when there is no active patent as

$$
V^{f}=\max _{\left\{u_{t}\right\}_{t=0}^{\infty}} \int_{0}^{\infty} Q\left(u_{t}\right) e^{-\int_{0}^{t}\left(u_{\tau}+r\right) d \tau} d t
$$

and write the continuation value $V\left(\rho_{n}, z_{n}\right)$ when there is active patent $z_{n}$ as

$$
V\left(\rho_{n}, z_{n}\right)=\frac{1}{r} \Delta\left(\rho_{n}, z_{n}\right)+\max _{\left\{u_{t}\right\}_{t=0}^{\infty}} \int_{0}^{T} Q\left(u_{t}\right) e^{-\int_{0}^{t}\left(u_{\tau}+r\right) d \tau} d t+e^{-\int_{0}^{T}\left(u_{\tau}+r\right) d \tau} V^{f}
$$

subject to the promise-keeping constraint (2). The detailed algebra of obtaining (36) and (37) is relegated to the Appendix which also contains the argument that in this setting the optimal policy is independent of $\left(\rho_{n}, z_{n}\right)$.

Similar to the setting with radical innovation, we define $u^{*}$ as

$$
u^{*} \in \arg \max _{u}[Q(u) /(u+r)]
$$

In other words,

$$
Q^{\prime}\left(u^{*}\right)\left(u^{*}+r\right)-Q\left(u^{*}\right)=0 .
$$

We define $u_{n}$ and $T^{*}$ as in 26) and 27).

Proposition 6 With incremental innovation, when there are no active patents, a stationary policy with $u_{t}=u^{*}$ for all $t$ is optimal.

This proposition is analogous to Proposition 1, and we omit its proof. A notable difference is that the optimal arrival rate $u^{*}$ is independent of the idea quality $z_{n}$ and the patent duration $\rho_{n}$ of the current patent. We also obtain an analogous relationship 
between $u^{*}$ and $V^{f}$ as described in 13$): Q^{\prime}\left(u^{*}\right)=V^{f}$. Our previous analysis with radical innovation applies with minor modifications. We state without proof the main result of this section.

Proposition 7 Suppose $Q$ is strictly concave. If $u^{*}<u_{n}$, then the optimal policy sets $T=T^{*}$ and $u(t)=u^{*}$ for all $t$. If $u^{*} \geq u_{n}$, then the optimal policy sets $T=\infty$ and $u(t)=u_{n}$ for all $t$.

This proposition is the counterpart of Proposition 4. The assumption of concave $Q$ can be relaxed using the convex-envelope approach we developed earlier.

We conclude this section with a comment on the choice of $T$. In HLM, ideas arrive exogenously, so the planner never needs to worry about the research incentives. Moreover, since there is no deadweight loss, and a larger patent duration yields stronger commercialization incentives, a patent should never expire before a new patentable idea arrives. In our model, the patent policy has an impact on research incentives as well, and the planner takes this effect into account when choosing the policy. As a result, the planner may want to restrict the size of the reward in order to curb socially excessive research.

\section{Concluding Remarks}

We build a sequential innovation model where both incentives and welfare costs are multidimensional. We characterize the optimal mix of patent length and breadth, identify a "replacement effect" from the planner's perspective, and demonstrate that the level and decomposition of the social surplus generated by innovation play different role in optimal patent design.

Several simplifying assumptions are made to facilitate our analysis. First, we assume that the current patent expires or terminates whenever a new patent is approved, so blocking patents are assumed away. We suspect that blocking patents should never be allowed in optimal patent policy under some general conditions, but we are unable to prove so. Second, we do not allow firms to bank ideas, so new ideas are either developed immediately or lost. Third, licensing is not allowed in our model. Relaxing some or all of the above assumptions would allow a more complete investigation of various tradeoffs in optimal patent design. Finally, our model treats research and development separately, so it is possible to introduce market for ideas into our model. We leave such extensions for future research. 


\section{Appendix: Proofs and Omitted Algebra}

Proof of Proposition 1. The planner's value function has an upperbound:

$$
\begin{aligned}
& \int_{0}^{\infty}\left[Q\left(u_{t}\right)+S\left(\rho_{n}, z_{n}\right)\right] e^{-\int_{0}^{t}\left(u_{\tau}+r\right) d \tau} d t \\
= & \int_{0}^{\infty} \frac{Q\left(u_{t}\right)+S\left(\rho_{n}, z_{n}\right)}{u_{t}+r}\left(u_{t}+r\right) e^{-\int_{0}^{t}\left(u_{\tau}+r\right) d \tau} d t \\
\leq & \left(\max _{u} \frac{Q(u)+S\left(\rho_{n}, z_{n}\right)}{u+r}\right) \int_{0}^{\infty}\left(u_{t}+r\right) e^{-\int_{0}^{t}\left(u_{\tau}+r\right) d \tau} d t \\
= & \max _{u} \frac{Q(u)+S\left(\rho_{n}, z_{n}\right)}{u+r} .
\end{aligned}
$$

The last equality follows from the fact that

$$
\int_{0}^{\infty}\left(u_{t}+r\right) e^{-\int_{0}^{t}\left(u_{\tau}+r\right) d \tau} d t=1 .
$$

This upperbound is achieved by setting $u_{t}=u^{*}\left(\rho_{n}, z_{n}\right)$ for all $t$.

Proof of Proposition 2, We use (14) to write Program $\mathcal{C}$ with infinite horizon as ${ }^{30}$

$$
\begin{aligned}
& \max _{u(t)} \int_{0}^{\infty}[Q(u(t))+C+P] x(t) d t \\
\text { subject to }: & \dot{x}(t)=-[u(t)+r] x(t) \\
: & \dot{y}(t)=x(t) \\
: & x_{0}=1 \text { and } x_{\infty} \text { free } \\
: & y_{0}=0 \text { and } y_{\infty}=\rho_{n} \\
: & u_{t} \in U \equiv\{u: 0 \leq u \leq \bar{\lambda}\}
\end{aligned}
$$

Let $\left(x_{\infty}(t), y_{\infty}(t)\right)$ denote the optimal path corresponding to our candidate control $u_{\infty}(t)=u_{n}$.

We apply the infinite horizon version of the Arrow sufficient theorem ${ }^{31}$ We first find a pair of continuous and piecewise continuously differentiable functions $p_{1 \infty}(t)$ and $p_{2 \infty}(t)$ that satisfy the following adjoint equations

$$
\begin{aligned}
& \dot{p}_{1 \infty}(t)=-Q\left(u_{n}\right)-C-P+p_{1 \infty}(t)\left(u_{n}+r\right)-p_{2 \infty}(t) \\
& \dot{p}_{2 \infty}(t)=0
\end{aligned}
$$

${ }^{30}$ Alternatively, we can formulate the objective function in Program $\mathcal{C}$ with infinite horizon as

$$
\int_{0}^{\infty}\left[Q(u(t))+C+P-(u(t)+r) V^{f}\right] x(t) d t+V^{f} .
$$

This formulation is closer to the one that we used to analyze the finite horizon case. The same procedure leads to the same characterization of the optimal policy.

${ }^{31}$ Theorem 14 in Seierstad and Sydsaeter (1987), page 236. 
and the maximum principle:

$$
H\left(x_{\infty}, y_{\infty}, u_{n}, p_{1 \infty}, p_{2 \infty}, t\right) \geq H\left(x_{\infty}, y_{\infty}, u, p_{1 \infty}, p_{2 \infty}, t\right) \text { for any feasible } u
$$

The maximum principle implies that

$$
\frac{\partial H\left(x_{\infty}, y_{\infty}, u_{n}, p_{1 \infty}, p_{2 \infty}, t\right)}{\partial u}=\left[Q^{\prime}\left(u_{n}\right)-p_{1 \infty}(t)\right] x_{\infty}(t)=0
$$

Therefore, $p_{1 \infty}(t)=Q^{\prime}\left(u_{n}\right)$, which implies that $\dot{p}_{1 \infty}(t)=0$. As a result, we obtain from the two adjoint conditions that

$$
\begin{aligned}
& p_{1 \infty}(t)=Q^{\prime}\left(u_{n}\right), \\
& p_{2 \infty}(t)=Q^{\prime}\left(u_{n}\right)\left(u_{n}+r\right)-Q\left(u_{n}\right)-C-P .
\end{aligned}
$$

It is straightforward to verify that these two functions indeed satisfy adjoint conditions and the maximum principle.

Next, we need to verify that these two functions satisfy the following transversality condition:

$$
0 \leq \lim _{t \rightarrow \infty}\left[p_{1 \infty}(t)\left(x(t)-x_{\infty}(t)\right)+p_{2 \infty}(t)\left(y(t)-y_{\infty}(t)\right)\right] \text { for all } x
$$

Note that

$$
\begin{aligned}
& \lim _{t \rightarrow \infty}\left[p_{1 \infty}(t)\left(x(t)-x_{\infty}(t)\right)+p_{2 \infty}(t)\left(y(t)-y_{\infty}(t)\right)\right] \\
= & \lim _{t \rightarrow \infty}\left\{Q^{\prime}\left(u_{n}\right)\left(x(t)-x_{\infty}(t)\right)+\left[Q^{\prime}\left(u_{n}\right)\left(u_{n}+r\right)-Q\left(u_{n}\right)-C-P\right]\left(y(t)-y_{\infty}(t)\right)\right\} \\
= & Q^{\prime}\left(u_{n}\right) \lim _{t \rightarrow \infty}\left(x(t)-x_{\infty}(t)\right)+\left[Q^{\prime}\left(u_{n}\right)\left(u_{n}+r\right)-Q\left(u_{n}\right)-C-P\right] \lim _{t \rightarrow \infty}\left(y(t)-y_{\infty}(t)\right) \\
= & 0 .
\end{aligned}
$$

The last equality follows because $x(t) \rightarrow 0, x_{\infty}(t) \rightarrow 0$ and $y(t) \rightarrow \rho_{n}$ as $t \rightarrow \infty$.

Finally, we need to verify the Arrow's concavity condition:

$$
\begin{aligned}
& \widehat{H}\left(x, y, p_{1 \infty}, p_{2 \infty}, t\right) \\
= & \max _{u} H\left(x, y, u, p_{1 \infty}, p_{2 \infty}, t\right) \\
= & \max _{u}\left\{[Q(u(t))+C+P] x(t)-p_{1 \infty}(t)[u(t)+r] x(t)+p_{2 \infty}(t) x(t)\right\} \\
= & \max _{u}\left\{[Q(u(t))+C+P] x(t)-Q^{\prime}\left(u_{n}\right)[u(t)+r] x(t)+\left[Q^{\prime}\left(u_{n}\right)\left(u_{n}+r\right)-Q\left(u_{n}\right)\right] x(t)\right\} \\
= & x(t) \max _{u}\left[Q(u(t))+C+P-Q\left(u_{n}\right)-Q^{\prime}\left(u_{n}\right)\left(u(t)-u_{n}\right)\right]
\end{aligned}
$$

The third equality follows by substituting expressions for $p_{1 \infty}(t)$ and $p_{2 \infty}(t)$. Thus, $\widehat{H}\left(x, y, p_{1}, p_{2}, t\right)$ satisfies the Arrow's concavity condition. Thus, $u_{\infty}(t)=u_{n}$ is optimal, and 28 follows by inserting $u_{\infty}(t)=u_{n}$ into the objective. 
Proof of Corollary 1. The social planner's optimization problem becomes

$$
\max _{\left\{u_{t}\right\}_{t=0}^{\infty}} \int_{0}^{\infty}\left[Q_{E}\left(u_{t}\right)+C+P\right] e^{-\int_{0}^{t}\left(u_{\tau}+r\right) d \tau} d t \text { subject to } \int_{0}^{\infty} e^{-\int_{0}^{s}\left(u_{\tau}+r\right) d \tau} d s=\rho_{n},
$$

where

$$
\begin{aligned}
Q_{E}\left(u_{t}\right) & \equiv \max _{\rho_{t}(\cdot)} Q_{E}\left(u_{t}, \rho_{t}(\cdot)\right) \\
& =\max _{\rho_{t}(\cdot)}\left\{u_{t} \mathbb{E}\left[V\left(\rho_{t}(\xi), \xi\right)-\kappa\left(\rho_{t}(\xi), \xi\right) \mid \xi \geq \Phi^{-1}\left(1-u_{t} / \lambda\right)\right]+C+P\right\}
\end{aligned}
$$

Let $\rho_{t}^{*}(\cdot)$ and $\widehat{z_{t}}$ denote the optimal reward function and cutoff function corresponding to the optimal arrival rate of ideas $u_{t}$. Then $\widehat{z}_{t}=\Phi^{-1}\left(1-u_{t} / \lambda\right)$ and

$$
\rho_{t}^{*}(\cdot)=\arg \max _{\rho_{t}(\cdot)} Q_{E}\left(u_{t}, \rho_{t}(\cdot)\right) .
$$

If we write $\eta(u) \equiv \widehat{z}_{t}(u)$, then by definition, $u=\lambda[1-\Phi(\eta(u))]$, which implies

$$
1=-\lambda \phi(\eta(u)) \eta^{\prime}(u) .
$$

By Proposition 2, it is sufficient to show that $Q_{E}\left(u_{t}\right)$ is concave in $u_{t}$. Note that $Q_{E}\left(u_{t}, \rho_{t}(\cdot)\right)$ can be written as

$$
Q_{E}\left(u_{t}, \rho_{t}(\cdot)\right)=\lambda \int_{\eta\left(u_{t}\right)}^{\infty}\left[V\left(\rho_{t}(\xi), \xi\right)-\kappa\left(\rho_{t}(\xi), \xi\right)\right] \phi(\xi) d \xi+C+P .
$$

Therefore, by applying envelope theorem to problem 40, we have

$$
\begin{aligned}
Q_{E}^{\prime}(u) & =\frac{\partial Q_{E}\left(u_{t}, \rho_{t}(\cdot)\right)}{\partial u_{t}} \\
& =-\lambda\left[V\left(\rho_{t}^{*}\left(\eta\left(u_{t}\right)\right), \eta\left(u_{t}\right)\right)-\kappa\left(\rho_{t}\left(\eta\left(u_{t}\right)\right), \eta\left(u_{t}\right)\right)\right] \phi\left(\eta\left(u_{t}\right)\right) \eta^{\prime}\left(u_{t}\right) \\
& =V\left(\rho_{t}^{*}\left(\eta\left(u_{t}\right)\right), \eta\left(u_{t}\right)\right)-\kappa\left(\rho_{t}^{*}\left(\eta\left(u_{t}\right)\right), \eta\left(u_{t}\right)\right) \\
Q_{E}^{\prime \prime}(u) & =-\frac{d\left[V\left(\rho_{t}^{*}\left(\eta\left(u_{t}\right)\right), \eta\left(u_{t}\right)\right)-\kappa\left(\rho_{t}^{*}\left(\eta\left(u_{t}\right)\right), \eta\left(u_{t}\right)\right)\right]}{d \eta(u)} \frac{1}{\lambda \phi\left(\eta\left(u_{t}\right)\right)} \\
& =-\frac{d\left[V\left(\rho_{t}^{*}\left(\widehat{z}_{t}\right), \widehat{z}_{t}\right)-\kappa\left(\rho_{t}^{*}\left(\widehat{z}_{t}\right), \widehat{z}_{t}\right)\right]}{d \widehat{z}_{t}} \frac{1}{\lambda \phi\left(\widehat{z}_{t}\right)}
\end{aligned}
$$

This implies that $Q_{E}$ is concave if $V\left(\rho_{t}^{*}\left(\widehat{z}_{t}\right), \widehat{z}_{t}\right)-\kappa\left(\rho_{t}^{*}\left(\widehat{z}_{t}\right), \widehat{z}_{t}\right)$ is increasing in $\widehat{z}_{t}$.

To show that $V\left(\rho_{t}^{*}\left(\widehat{z}_{t}\right), \widehat{z}_{t}\right)-\kappa\left(\rho_{t}^{*}\left(\widehat{z}_{t}\right), \widehat{z}_{t}\right)$ is increasing in $\widehat{z}_{t}$, suppose the opposite is true. That is, $V\left(\rho_{t}^{*}\left(\widehat{z}_{t}\right), \widehat{z}_{t}\right)-\kappa\left(\rho_{t}^{*}\left(\widehat{z}_{t}\right), \widehat{z}_{t}\right)$ is strictly decreasing around some $\widehat{z}_{t}$. Therefore, we have a $\widehat{z}_{t}$ and a $\widehat{z}_{t}^{\prime}>\widehat{z}_{t}$, such that

$$
V\left(\rho_{t}^{*}\left(\widehat{z}_{t}\right), \widehat{z}_{t}\right)-\kappa\left(\rho_{t}^{*}\left(\widehat{z}_{t}\right), \widehat{z}_{t}\right)>V\left(\widetilde{\rho}_{t}^{*}\left(\widehat{z}_{t}^{\prime}\right), \widehat{z}_{t}^{\prime}\right)-\kappa\left(\widetilde{\rho}_{t}^{*}\left(\widehat{z}_{t}^{\prime}\right), \widehat{z}_{t}^{\prime}\right)
$$


where $\rho_{t}^{*}$ is the optimal reward function corresponding to $\widehat{z}_{t}$, and $\widetilde{\rho}_{t}^{*}$ is the optimal reward function corresponding to $\widehat{z}_{t}^{\prime}$. Consider the following deviation: If idea $\widehat{z}^{\prime}$ arrives at time $t$, provide it with protection $\rho_{t}^{*}\left(\widehat{z}_{t}\right)$ instead of $\widetilde{\rho}_{t}^{*}\left(\widehat{z}_{t}^{\prime}\right)$. Since, everything else equal, a better idea must deliver a higher continuation value minus development cost (lower innovation cost or higher benefit), we must have

$$
V\left(\rho_{t}^{*}\left(\widehat{z}_{t}\right), \widehat{z}_{t}\right)-\kappa\left(\rho_{t}^{*}\left(\widehat{z}_{t}\right), \widehat{z}_{t}\right)<V\left(\rho_{t}^{*}\left(\widehat{z}_{t}\right), \widehat{z}_{t}^{\prime}\right)-\kappa\left(\rho_{t}^{*}\left(\widehat{z}_{t}\right), \widehat{z}_{t}^{\prime}\right)
$$

Together with (41), this implies that

$$
V\left(\widetilde{\rho}_{t}^{*}\left(\widehat{z}_{t}^{\prime}\right), \widehat{z}_{t}^{\prime}\right)-\kappa\left(\widetilde{\rho}_{t}^{*}\left(\widehat{z}_{t}^{\prime}\right), \widehat{z}_{t}^{\prime}\right)<V\left(\rho_{t}^{*}\left(\widehat{z}_{t}\right), \widehat{z}_{t}^{\prime}\right)-\kappa\left(\rho_{t}^{*}\left(\widehat{z}_{t}\right), \widehat{z}_{t}^{\prime}\right)
$$

Thus $\widetilde{\rho}_{t}^{*}\left(\widehat{z}_{t}^{\prime}\right)$ cannot be optimal. Therefore, $V\left(\rho_{t}^{*}\left(\widehat{z}_{t}\right), \widehat{z}_{t}\right)-\kappa\left(\rho_{t}^{*}\left(\widehat{z}_{t}\right), \widehat{z}_{t}\right)$ must be increasing. Thus $Q_{E}(u)$ is concave.

Proof of Proposition 3. The proof consists of two steps. First we apply Arrow Sufficiency Theorem with finite horizon to characterize optimal policy when $T$ is exogenous and finite. Second, we apply Arrow Sufficiency Theorem with free terminal time to characterize optimal policy when $T$ is optimally chosen and finite.

Step One. We claim that, if $Q$ is strictly concave and $T^{*}<\infty$, the continuous optimal control that solves Program $\mathcal{C}$ with fixed $T \in[0, \infty)$ must have the following properties: (a) If $T>T^{*}, u_{T}(t)$ must start at $u_{T}(0)>u^{*}$ and reach $u^{*}$ from above at time $T$; (b) If $T=T^{*}, u_{T}(t)$ must start at $u_{T}(0)=u^{*}$ and remain there until time $T$; and (c) If $T<T^{*}, u_{T}(t)$ must start at $u_{T}(0)<u^{*}$ and reach $u^{*}$ from below at time $T$.

To verify the above claim, recall that the Hamiltonian is given by

$$
H\left(x_{T}, y_{T}, u_{T}, p_{1 T}, p_{2 T}, t\right)=\left[Q\left(u_{T}(t)\right)+C+P-\left(u_{T}(t)+r\right)\left(V^{f}+p_{1 T}(t)\right)+p_{2 T}(t)\right] x_{T}(t) .
$$

We first apply the optimal control theorem of necessary conditions to characterize the property of optimal control $u_{T}(t){ }^{32}$ Let $\left(x_{T}(t), y_{T}(t)\right)$ defined on $[0, T]$ be the optimal path associated with $u_{T}(t)$. Then there exists continuous and piecewise continuously differentiable $p_{1 T}(t)$ and $p_{2 T}(t)$ such that

$$
\begin{aligned}
\dot{p}_{1 T}(t) & =-\frac{\partial H\left(x_{T}, y_{T}, u_{T}, p_{1}, p_{2}, t\right)}{\partial x} \\
& =-Q\left(u_{T}(t)\right)-C-P+\left(u_{T}(t)+r\right)\left(V^{f}+p_{1 T}(t)\right)-p_{2 T}(t) \\
\dot{p}_{2 T}(t) & =-\frac{\partial H\left(x_{T}, y_{T}, u_{T}, p_{1}, p_{2}, t\right)}{\partial y}=0
\end{aligned}
$$

\footnotetext{
${ }^{32}$ Theorem 2 in Seierstad and Sydsaeter (1987), page 85.
} 
Moreover, the maximum principle implies that

$$
\left\{\begin{array}{llc}
p_{1 T}(t) \geq Q^{\prime}\left(u_{T}(t)\right)-V^{f} & \text { if } & u_{T}(t)=0 \\
p_{1 T}(t)=Q^{\prime}\left(u_{T}(t)\right)-V^{f} & \text { if } & u_{T}(t) \in(0, \bar{\lambda}) \\
p_{1 T}(t) \leq Q^{\prime}\left(u_{T}(t)\right)-V^{f} & \text { if } & u_{T}(t)=\bar{\lambda}
\end{array}\right.
$$

Finally, $p_{1 T}(t)$ must satisfy the following transversality conditions:

$$
p_{1 T}(T)=0
$$

Note that 44 implies that, for all $t$,

$$
p_{2 T}(t)=\bar{p}_{2 T}
$$

for some constant $\bar{p}_{2 T} \geq 0$. By condition (46), we have $p_{1 T}(T)=0$. Therefore, by definition of $u^{*}$ and the fact that $u^{*} \in(0, \bar{\lambda})$, condition 45 immediately implies that

$$
u_{T}(T)=u^{*}
$$

Moreover, condition (45) also implies that, when $u_{T}(t)$ is interior, $u_{T}(t)$ is continuous because $p_{1 T}(t)$ is piecewise continuously differentiable.

Suppose for some $t$, the optimal control $u_{T}(t)$ is interior, that is, $u_{T}(t) \in(0, \bar{\lambda})$. It follows from condition (45) that, at points where $p_{1 T}(t)$ is differentiable,

$$
\dot{p}_{1 T}(t)=Q^{\prime \prime}\left(u_{T}(t)\right) \dot{u}_{T}(t) \text {. }
$$

Hence $u_{T}(t)$ is differentiable at points where $p_{1 T}(t)$ is differentiable. Moreover, 45) and 47) establish that

$$
\dot{p}_{1 T}(t)=-Q\left(u_{T}(t)\right)-C-P+\left(u_{T}(t)+r\right) Q^{\prime}\left(u_{T}(t)\right)-\bar{p}_{2 T}
$$

This equation, together with (49), implies that $p_{1 T}(t)$ is twice differentiable at points where $p_{1 T}(t)$ is differentiable. Therefore,

$$
\ddot{p}_{1 T}(t)=\left(u_{T}(t)+r\right) \dot{p}_{1 T}(t) \text {. }
$$

This condition implies that $\dot{p}_{1 T}(t)$ never changes sign. It follows from 49 that $\dot{u}_{T}(t)$ does not change sign either. Therefore, $u_{T}(t)$ is either always weakly increasing or weakly decreasing for all $t \in[0, T]$. It follows immediately from the anchor condition (48) and the promise-keeping constraint that the optimal control must take the form specified in the proposition.

Next, we verify that the described candidate control is indeed the solution to Program $\mathcal{C}$ with fixed and finite $T$ by appealing to the finite horizon version of the Arrow sufficiency 
theorem ${ }^{33}$ The sufficiency theorem claims that if the triple $\left(x_{T}(t), y_{T}(t), u_{T}(t)\right)$ defined on $[0, T]$ satisfies not only the necessary conditions but also the following Arrow concavity condition:

$$
\widehat{H}\left(x, y, p_{1 T}, p_{2 T}, t\right) \text { exists and is concave in } x, y \text { for all } t \in[0, T]
$$

then $\left(x_{T}(t), y_{T}(t), u_{T}(t)\right)$ solves Program $\mathcal{C}$. The proof takes advantage of two special features of our Hamiltonian given in (24). First, it is concave in $u$ if $Q$ is concave, so its maximizer is characterized by its first-order condition. Second, it is linear in $x_{T}(t)$ and does not contain $y_{T}(t)$, so the Arrow concavity condition is trivially satisfied.

The functions $p_{1 T}(t)$ and $p_{2 T}(t)$ defined by (45) and (47) clearly satisfy (43), (44), and (46). We need to verify that they also satisfy the maximum principle. Note that

$$
\frac{\partial H\left(x_{T}, y_{T}, u, p_{1 T}, p_{2 T}, t\right)}{\partial u}=\left[Q^{\prime}(u)-\left(V^{f}+p_{1 T}(t)\right)\right] x_{T}(t),
$$

and $H$ is concave in $u$ by the concavity of $Q$. Therefore, the described optimal control maximizes the Hamiltonian. Finally, we need to verify the Arrow's concavity condition. Note that

$$
\begin{aligned}
\widehat{H}\left(x, y, p_{1 T}, p_{2 T}, t\right) & =\max _{u} H\left(x, y, u, p_{1 T}, p_{2 T}, t\right) \\
& =\max _{u}\left[Q(u)+C+P-(u+r)\left(V^{f}+p_{1 T}(t)\right)+p_{2 T}(t)\right] x(t) \\
& =x(t) \max _{u}\left[Q(u)+C+P-(u+r) Q^{\prime}\left(u_{T}(t)\right)+\bar{p}_{2 T}\right]
\end{aligned}
$$

which is always linear in $x$. Thus, $\widehat{H}\left(x, y, p_{1}, p_{2}, t\right)$ satisfies the Arrow's concavity condition. Therefore, $\left(x_{T}(t), y_{T}(t), u_{T}(t)\right)$ solves Program $\mathcal{C}$ with fixed $T \in[0, \infty)$.

Step Two. By the claim in the previous step, we can set

$$
p_{1 T}(t)=Q^{\prime}\left(u_{T}(t)\right)-V^{f}, p_{2 T}(t)=\bar{p}_{2 T}, u_{T}(T)=u^{*}
$$

In particular, when $T$ is fixed at $T^{*}, u_{T^{*}}(t)=u^{*}$ for all $t \in\left[0, T^{*}\right]$. Therefore, we have $p_{1 T^{*}}(t)=Q^{\prime}\left(u^{*}\right)-V^{f}=0$ and thus $\dot{p}_{1 T^{*}}(t)=0$. The adjoint equation involving $p_{1 T^{*}}(t)$ is given by 43 :

$$
\dot{p}_{1 T^{*}}(t)=-Q\left(u^{*}\right)-C-P+\left(u^{*}+r\right)\left(V^{f}+p_{1 T^{*}}(t)\right)-p_{2 T^{*}}(t)
$$

It follows that

$$
\bar{p}_{2 T^{*}}=-Q\left(u^{*}\right)-C-P+\left(u^{*}+r\right)\left(V^{f}+p_{1 T^{*}}(t)\right)=-Q\left(u^{*}\right)+\left(u^{*}+r\right) Q^{\prime}\left(u^{*}\right) .
$$

\footnotetext{
${ }^{33}$ Theorem 5 in Seierstad and Sydsaeter (1987), page 107.
} 
It remains to verify condition $(29)$. Note that, for interior $u_{T}(t)$, we can obtain the following ordinary differential equation from (43), (44) and (45):

$$
\dot{u}_{T}(t)=\frac{1}{Q^{\prime \prime}\left(u_{T}(t)\right)}\left[-Q\left(u_{T}(t)\right)-C-P+\left(u_{T}(t)+r\right) Q^{\prime}\left(u_{T}(t)\right)-\bar{p}_{2 T}\right],
$$

It follows from step one that, at points where $u_{T}(t)$ is differentiable, $\dot{u}_{T^{*}}(t)=0, \dot{u}_{T}(t) \leq 0$ if $T>T^{*}$ and $\dot{u}_{T}(t) \geq 0$ if $T<T^{*}$, and the inequality must be strict for some $t$. It follows from (51), 13) and (12) that

$$
\bar{p}_{2 T^{*}}=-Q\left(u^{*}\right)-C-P+\left(u^{*}+r\right) Q^{\prime}\left(u^{*}\right)=\chi\left(\rho_{n}, z_{n}\right)
$$

Equation (51) and boundary condition $\left(u_{T}(T)=u^{*}\right)$ then imply that $\bar{p}_{2 T}<\bar{p}_{2 T^{*}}$ if $T>T^{*}$ and $\bar{p}_{2 T}>\bar{p}_{2 T^{*}}$ if $T<T^{*}$.

Further recall that the Hamiltonian is given by

$H\left(x_{T}, y_{T}, u_{T}, p_{1 T}, p_{2 T}, t\right)=\left[Q\left(u_{T}(t)\right)+C+P-\left(u_{T}(t)+r\right)\left(V^{f}+p_{1 T}(t)\right)+p_{2 T}(t)\right] x_{T}(t)$.

By definition of $F(T)$, we have

$$
F(T)=\left[Q\left(u^{*}\right)+C+P-\left(u^{*}+r\right) Q^{\prime}\left(u^{*}\right)+\bar{p}_{2 T}\right] x_{T}(T) .
$$

Therefore,

$$
F\left(T^{*}\right)=\left[Q\left(u^{*}\right)+C+P-\left(u^{*}+r\right) Q^{\prime}\left(u^{*}\right)+\bar{p}_{2 T^{*}}\right] x_{T^{*}}\left(T^{*}\right)=0 .
$$

Therefore, for all $T<T^{*}$,

$$
F(T)=\left[Q\left(u^{*}\right)+C+P-\left(u^{*}+r\right) Q^{\prime}\left(u^{*}\right)+\bar{p}_{2 T}\right] x_{T}(T)>0 .
$$

For all $T>T^{*}$,

$$
F(T)=\left[Q\left(u^{*}\right)+C+P-\left(u^{*}+r\right) Q^{\prime}\left(u^{*}\right)+\bar{p}_{2 T}\right] x_{T}(T)<0 .
$$

Since condition (29) holds, we conclude that $T=T^{*}$ and $u_{T^{*}}(t)=u^{*}$ for all $t \in\left[0, T^{*}\right]$ solve Program $\mathcal{C}$ with free terminal time $T$.

In order to obtain (30), we insert the optimal solution with finite $T^{*}$ back into the objective function to obtain

$$
V\left(\rho_{n}, z_{n}\right)=\left[Q\left(u^{*}\right)+C\left(\rho_{n}, z_{n}\right)+P\left(\rho_{n}, z_{n}\right)\right] \rho_{n}+e^{-\left(u^{*}+r\right) T^{*}} V^{f}\left(\rho_{n}, z_{n}\right)
$$

We apply (27) and (12) to obtain

$$
\begin{aligned}
V\left(\rho_{n}, z_{n}\right)= & {\left[Q\left(u^{*}\right)+S\left(\rho_{n}, z_{n}\right)-\chi\left(\rho_{n}, z_{n}\right)\right]\left(1-e^{-\left(u^{*}+r\right) T^{*}}\right) /\left(u^{*}+r\right) } \\
& +e^{-\left(u^{*}+r\right) T^{*}} V^{f}\left(\rho_{n}, z_{n}\right) \\
= & \left(1-e^{-\left(u^{*}+r\right) T^{*}}\right) V^{f}\left(\rho_{n}, z_{n}\right)-\chi\left(\rho_{n}, z_{n}\right) \rho_{n}+e^{-\left(u^{*}+r\right) T^{*}} V^{f}\left(\rho_{n}, z_{n}\right) \\
= & V^{f}\left(\rho_{n}, z_{n}\right)-\chi\left(\rho_{n}, z_{n}\right) \rho_{n},
\end{aligned}
$$


which is exactly 30 .

Proof of Proposition 4. First consider the case with $u^{*}<u_{n}$. In this case, $T^{*}<\infty$. Therefore, the optimal policy with $T<\infty$ will set $T=T^{*}$ and the value function is

$$
\begin{aligned}
V\left(\rho_{n}, z_{n}\right) & =\int_{0}^{T^{*}}\left[Q\left(u^{*}\right)+C+P\right] e^{-\int_{0}^{t}\left(u^{*}+r\right) d \tau} d t+V^{f}\left(\rho_{n}, z_{n}\right) e^{-\int_{0}^{T}\left(u^{*}+r\right) d \tau} \\
& =\left[Q\left(u^{*}\right)+C+P\right] \rho_{n}+V^{f}\left(\rho_{n}, z_{n}\right) e^{-\left(u^{*}+r\right) T^{*}} \\
& =\left[Q\left(u^{*}\right)+C+P\right] \rho_{n}+Q^{\prime}\left(u^{*}\right)\left[1-\rho_{n}\left(u^{*}+r\right)\right] \\
& =\left[Q\left(u^{*}\right)+C+P\right] \frac{1}{u_{n}+r}+Q^{\prime}\left(u^{*}\right)\left(\frac{u_{n}-u^{*}}{u_{n}+r}\right) \\
& =\frac{1}{u_{n}+r}\left[Q\left(u^{*}\right)+C+P+Q^{\prime}\left(u^{*}\right)\left(u_{n}-u^{*}\right)\right]
\end{aligned}
$$

By concavity of $Q$, we have

$$
V\left(\rho_{n}, z_{n}\right)-V^{\infty}\left(\rho_{n}, z_{n}\right)=\frac{1}{u_{n}+r}\left[Q\left(u^{*}\right)+Q^{\prime}\left(u^{*}\right)\left(u_{n}-u^{*}\right)-Q\left(u_{n}\right)\right]>0 .
$$

Therefore, $T=T^{*}$ and $u(t)=u^{*}$.

Next consider the case with $u^{*} \geq u_{n}$. In this case, $T^{*}$ is not well-defined. Consider the optimal policy with fixed $T<\infty$. Given the promise-keeping constraint and our assumption that $u^{*} \geq u_{n}$, it follows from the proof for Proposition 3 that the only possible path for optimal $u_{T}(t)$ is that $u_{T}(t)$ starts at $u_{T}(0)<u^{*}$, increasing continuously and approaching $u^{*}$ from below at time $T$. Therefore, there exists a time $T_{0} \in(0, T)$ such that

$$
\left\{\begin{array}{ll}
u_{T}(t) \leq u_{n} & \text { if } \quad t \leq T_{0} \\
u_{T}(t) \geq u_{n} & \text { if } \quad t \geq T_{0}
\end{array} .\right.
$$

In order to prove that the optimal policy sets $T=\infty$ and $u(t)=u_{n}$ for all $t$, it is sufficient to show that $V\left(\rho_{n}, z_{n}\right)-V^{\infty}\left(\rho_{n}, z_{n}\right) \leq 0$. Note that

$$
\begin{aligned}
& V\left(\rho_{n}, z_{n}\right)-V^{\infty}\left(\rho_{n}, z_{n}\right) \\
= & \int_{0}^{T}\left[Q\left(u_{T}(t)\right)+C+P-\left(u_{T}(t)+r\right) V^{f}\right] e^{-\int_{0}^{t}\left(u_{T}(\tau)+r\right) d \tau} d t+V^{f}\left(\rho_{n}, z_{n}\right)-\frac{Q\left(u_{n}\right)+C+P}{u_{n}+r} \\
= & \int_{0}^{T}\left[Q\left(u_{T}(t)\right)+C+P-\left(u_{T}(t)+r\right) Q^{\prime}\left(u^{*}\right)\right] e^{-\int_{0}^{t}\left(u_{T}(\tau)+r\right) d \tau} d t+Q^{\prime}\left(u^{*}\right)-\frac{Q\left(u_{n}\right)+C+P}{u_{n}+r} \\
= & \int_{0}^{T}\left[Q\left(u_{T}(t)\right)+C+P+Q^{\prime}\left(u^{*}\right)\left(u_{n}-u_{T}(t)\right)-Q\left(u_{n}\right)-C-P\right] e^{-\int_{0}^{t}\left(u_{T}(\tau)+r\right) d \tau} d t \\
= & \int_{0}^{T_{0}}\left[Q\left(u_{T}(t)\right)+Q^{\prime}\left(u^{*}\right)\left(u_{n}-u_{T}(t)\right)-Q\left(u_{n}\right)\right] e^{-\int_{0}^{t}\left(u_{T}(\tau)+r\right) d \tau} d t \\
& +\int_{T_{0}}^{T}\left[Q\left(u_{T}(t)\right)+Q^{\prime}\left(u^{*}\right)\left(u_{n}-u_{T}(t)\right)-Q\left(u_{n}\right)\right] e^{-\int_{0}^{t}\left(u_{T}(\tau)+r\right) d \tau} d t
\end{aligned}
$$


It follows from the concavity of $Q$ that

$$
\begin{aligned}
& V\left(\rho_{n}, z_{n}\right)-V^{\infty}\left(\rho_{n}, z_{n}\right) \\
\leq & \int_{0}^{T_{0}}\left[Q\left(u_{T}(t)\right)+Q^{\prime}\left(u_{n}\right)\left(u_{n}-u_{T}(t)\right)-Q\left(u_{n}\right)\right] e^{-\int_{0}^{t}\left(u_{T}(\tau)+r\right) d \tau} d t \\
& +\int_{T_{0}}^{T}\left[Q\left(u_{T}(t)\right)+Q^{\prime}\left(u_{n}\right)\left(u_{n}-u_{T}(t)\right)-Q\left(u_{n}\right)\right] e^{-\int_{0}^{t}\left(u_{T}(\tau)+r\right) d \tau} d t \\
= & \int_{0}^{T}\left[Q\left(u_{T}(t)\right)+Q^{\prime}\left(u_{n}\right)\left(u_{n}-u_{T}(t)\right)-Q\left(u_{n}\right)\right] e^{-\int_{0}^{t}\left(u_{T}(\tau)+r\right) d \tau} d t \\
\leq & 0
\end{aligned}
$$

This completes the proof.

Proof of Proposition 5. Finite Horizon $\left(T^{*}<\infty\right)$. By definition, $u^{*}$ is the minimal solution to the following equation:

$$
\bar{Q}^{\prime}\left(u^{*}\right)=V^{f}\left(\rho_{n}, z_{n}\right)
$$

Therefore, $u^{*}$ must either lie on a non-linear segment or lie on the lower end point of a linear segment. This implies that $\bar{Q}\left(u^{*}\right)=Q\left(u^{*}\right)$. Therefore, optimal policy set $u(t)=u^{*}$ for all $t$ and $T=T^{*}$.

Infinite Horizon. If $Q\left(u_{n}\right)=\bar{Q}\left(u_{n}\right)$ then $\bar{V}\left(\rho_{n}, z_{n}\right)=V\left(\rho_{n}, z_{n}\right)$, because $\bar{V}\left(\rho_{n}, z_{n}\right)$ is attained under $Q(u)$ by simply setting $u(t)=u_{n}$. If $Q\left(u_{n}\right) \neq \bar{Q}\left(u_{n}\right)$, then $\bar{Q}\left(u_{n}\right)$ must lie on a linear segment of $\bar{Q}(u)$. Let $\bar{Q}\left(u_{1}\right)$ and $\bar{Q}\left(u_{2}\right)$ denote the two end points of this linear segment, with $u_{1}<u_{n}<u_{2}$. By definition of linear segment, $\bar{Q}\left(u_{1}\right)=Q\left(u_{1}\right)$ and $\bar{Q}\left(u_{2}\right)=Q\left(u_{2}\right)$. Geometrically, we must have

$$
\bar{Q}\left(u_{n}\right)=Q\left(u_{1}\right)+\frac{Q\left(u_{2}\right)-Q\left(u_{1}\right)}{u_{2}-u_{1}}\left(u_{n}-u_{1}\right) .
$$

Therefore,

$$
\bar{V}\left(\rho_{n}, z_{n}\right)=\rho_{n}\left[\bar{Q}\left(u_{n}\right)+C+P\right]=\rho_{n}\left[Q\left(u_{1}\right)+\frac{Q\left(u_{2}\right)-Q\left(u_{1}\right)}{u_{2}-u_{1}}\left(u_{n}-u_{1}\right)+C+P\right] .
$$

Consider the following $\left(u_{1}, u_{2}\right)$ policy which is feasible under $Q(u)$ :

$$
u(t)=\left\{\begin{array}{ll}
u_{1} & \text { if } t \leq \tau \\
u_{2} & \text { if } t>\tau
\end{array},\right.
$$

where the transition time $\tau$ is such that the promise-keeping constraint is satisfied:

$$
\rho_{n}=\left(1-e^{-\left(u_{1}+r\right) \tau}\right) \frac{1}{u_{1}+r}+e^{-\left(u_{1}+r\right) \tau} \frac{1}{u_{2}+r} .
$$


Therefore, by definition of $V\left(\rho_{n}, z_{n}\right)$,

$$
\begin{aligned}
& V\left(\rho_{n}, z_{n}\right) \geq \int_{0}^{\tau}\left[Q\left(u_{1}\right)+C+P\right] e^{-\left(u_{1}+r\right) s} d s+e^{-\left(u_{1}+r\right) \tau} \int_{\tau}^{\infty}\left[Q\left(u_{2}\right)+C+P\right] e^{-\left(u_{2}+r\right)(s-\tau)} d s \\
& =Q\left(u_{1}\right)\left(1-e^{-\left(u_{1}+r\right) \tau}\right) \frac{1}{u_{1}+r}+Q\left(u_{2}\right) e^{-\left(u_{1}+r\right) \tau} \frac{1}{u_{2}+r}+(C+P) \rho_{n} \\
& =Q\left(u_{1}\right) \rho_{n}+\left[Q\left(u_{2}\right)-Q\left(u_{1}\right)\right] e^{-\left(u_{1}+r\right) \tau} \frac{1}{u_{2}+r}+(C+P) \rho_{n} \\
& =Q\left(u_{1}\right) \rho_{n}+\left[Q\left(u_{2}\right)-Q\left(u_{1}\right)\right] \frac{\frac{1}{u_{1}+r}-\frac{1}{u_{n}+r}}{\frac{1}{u_{1}+r}-\frac{1}{u_{2}+r}} \frac{1}{u_{2}+r}+(C+P) \rho_{n} \\
& =\rho_{n}\left[Q\left(u_{1}\right)+\frac{Q\left(u_{2}\right)-Q\left(u_{1}\right)}{u_{2}-u_{1}}\left(u_{n}-u_{1}\right)+C+P\right] \\
& =\bar{V}\left(\rho_{n}, z_{n}\right)
\end{aligned}
$$

Hence, we conclude $V\left(\rho_{n}, z_{n}\right)=\bar{V}\left(\rho_{n}, z_{n}\right)$ for $T=\infty$.

Algebra for (35). Recall that with finite patent length, we have

$$
V(\rho, z)=V^{f}(\rho, z)-\rho \chi(\rho, z),
$$

and

$$
V^{f}(\rho, z)=\frac{Q\left(u^{*}(\rho, z)\right)+S(\rho, z)}{u^{*}(\rho, z)+r},
$$

with $Q^{\prime}\left(u^{*}(\rho, z)\right)=V^{f}(\rho, z)$. Therefore, applying envelope theorem to $V^{f}$, we have

$$
V_{\rho}(\rho, z)=V_{\rho}^{f}(\rho, z)-\chi(\rho, z)-\rho \chi_{\rho}(\rho, z)=\frac{S_{\rho}(\rho, z)}{u^{*}(\rho, z)+r}-\chi(\rho, z)-\rho \chi_{\rho}(\rho, z)
$$

Furthermore, it follows from the first-order condition of the firm's development investment decision that

$$
\rho \frac{\partial \widehat{\pi}}{\partial \kappa}-1=0 \Rightarrow \rho \frac{\partial \widehat{\pi}}{\partial \kappa}=1
$$

It follows from the definition of producer surplus (5) that $\pi_{\rho}(\rho, z)=P(\rho, z)$ and

$$
P_{\rho}(\rho, z)=\frac{\partial \widehat{\pi}}{\partial \kappa} \kappa_{\rho}(\rho, z) .
$$

Hence, we have

$$
\kappa_{\rho}(\rho, z)=\rho P_{\rho}(\rho, z)
$$

Therefore, we can rewrite $V_{\rho}(\rho, z)-\kappa_{\rho}(\rho, z)-\pi_{\rho}(\rho, z)$ as

$$
\begin{aligned}
& \frac{S_{\rho}(\rho, z)}{u^{*}(\rho, z)+r}-\chi(\rho, z)-\rho \chi_{\rho}(\rho, z)-\kappa_{\rho}(\rho, z)-P(\rho, z) \\
= & \frac{S_{\rho}(\rho, z)}{u^{*}(\rho, z)+r}-\chi(\rho, z)-\rho \chi_{\rho}(\rho, z)-\rho P_{\rho}(\rho, z)-P(\rho, z) \\
= & \rho C_{\rho}(\rho, z)-\chi(\rho, z)+\left(\frac{1}{u^{*}(\rho, z)+r}-\rho\right) S_{\rho}(\rho, z)-P(\rho, z)
\end{aligned}
$$


which is exactly (35).

Algebra for (36) and (37). We first formulate the continuation value when there is no active patent, which is given by

$$
V^{f}\left(\rho_{n}, z_{n}\right) \equiv \max _{\mathcal{P}} \int_{0}^{\infty}\left\{u_{t} \mathbb{E}\left[V\left(\rho_{t}(\xi), \xi\right)-\kappa\left(\rho_{t}(\xi), \xi\right) \mid \xi \geq \widehat{z}_{t}\right]-K\left(\rho_{t}(\cdot), \widehat{z}_{t}\right)\right\} e^{-\int_{0}^{t}\left(u_{\tau}+r\right) d \tau} d t
$$

We use the free-entry condition (3) to rewrite it as

$V^{f}\left(\rho_{n}, z_{n}\right) \equiv \max _{\mathcal{P}} \int_{0}^{\infty}\left\{u_{t} \mathbb{E}\left[V\left(\rho_{t}(\xi), \xi\right)-\kappa\left(\rho_{t}(\xi), \xi\right)-\pi\left(\rho_{t}(\xi), \xi\right) \mid \xi \geq \widehat{z}_{t}\right]\right\} e^{-\int_{0}^{t}\left(u_{\tau}+r\right) d \tau} d t$

Note that $\rho_{n}$ and $z_{n}$ enter the value function $V^{f}$ only through policy instruments $u_{t}, \widehat{z}_{t}$ and $\rho_{t}(z)$. It follows that the optimal patent policy and the continuation value $V^{f}\left(\rho_{n}, z_{n}\right)$ must be independent of $\rho_{n}$ and $z_{n}$. To see this, suppose that, for some $\left(\rho_{n}, z_{n}\right) \neq\left(\rho_{n}^{\prime}, z_{n}^{\prime}\right)$, $V^{f}\left(\rho_{n}, z_{n}\right) \neq V^{f}\left(\rho_{n}^{\prime}, z_{n}^{\prime}\right)$. Without loss, assume that $V^{f}\left(\rho_{n}, z_{n}\right)>V^{f}\left(\rho_{n}^{\prime}, z_{n}^{\prime}\right)$. Let $\mathcal{P}\left(\rho_{n}, z_{n}\right)$ and $\mathcal{P}\left(\rho_{n}^{\prime}, z_{n}^{\prime}\right)$ denote the optimal policy that attains $V^{f}\left(\rho_{n}, z_{n}\right)$ and $V^{f}\left(\rho_{n}^{\prime}, z_{n}^{\prime}\right)$, respectively. Note that policy $\mathcal{P}\left(\rho_{n}, z_{n}\right)$ is also feasible when the previous patent is $z_{n}^{\prime}$ with patent duration $\rho_{n}^{\prime}$, a contradiction to the fact that $\mathcal{P}\left(\rho_{n}^{\prime}, z_{n}^{\prime}\right)$ is optimal. Therefore, we can write $V^{f}$ as the continuation value to the planner in the absence of an active patent.

The continuation value $V\left(\rho_{n}, z_{n}\right)$, when there is an active patent $z_{n}$ with protection $\rho_{n}$, is given by

$$
\begin{aligned}
V\left(\rho_{n}, z_{n}\right)= & \frac{1}{r} \Delta\left(\rho_{n}, z_{n}\right) \\
& +\max _{\mathcal{P}}\left\{\begin{array}{c}
\int_{0}^{T}\left\{u_{t}\left\{\mathbb{E}\left[V\left(\rho_{t}(\xi), \xi\right)-\kappa\left(\rho_{t}(\xi), \xi\right) \mid \xi \geq \widehat{z}_{t}\right]\right\}\right\} e^{-\int_{0}^{t}\left(u_{\tau}+r\right) d \tau} d t \\
-\int_{0}^{T} K\left(\rho_{t}(\cdot), \widehat{z}_{t}\right) e^{-\int_{0}^{t}\left(u_{\tau}+r\right) d \tau} d t+e^{-\int_{0}^{T}\left(u_{\tau}+r\right) d \tau} V^{f}
\end{array}\right\} .
\end{aligned}
$$

subject to the promise-keeping constraint (2). Again we use the free-entry condition to rewrite it as

$$
\begin{aligned}
& V\left(\rho_{n}, z_{n}\right)=\frac{1}{r} \Delta\left(\rho_{n}, z_{n}\right) \\
& +\max _{\mathcal{P}}\left\{\begin{array}{c}
\int_{0}^{T} u_{t} \mathbb{E}\left[V\left(\rho_{t}(\xi), \xi\right)-\kappa\left(\rho_{t}(\xi), \xi\right)-\pi\left(\rho_{t}(\xi), \xi\right) \mid \xi \geq \widehat{z}_{t}\right] e^{-\int_{0}^{t}\left(u_{\tau}+r\right) d \tau} d t \\
+e^{-\int_{0}^{T}\left(u_{\tau}+r\right) d \tau} V^{f}
\end{array}\right\} .
\end{aligned}
$$

subject to the promise-keeping constraint (2). Using an analogous argument, we can show that the optimal policy must be independent of $\rho_{n}$ and $z_{n}$. Once we reformulate $V^{f}$ and $V\left(\rho_{n}, z_{n}\right)$ using notation $Q$, the expressions (36) and (37) immediately follow. 


\section{References}

[1] Acemoglu, Daron, and Ufuk Akcigit (2011), "Intellectual Property Rights Policy, Competition and Innovation," Journal of the European Economic Association, forthcoming.

[2] Acemoglu, Daron, and Dan Cao (2011), "Innovation by Incumbents and Entrants," Working Paper, MIT.

[3] Aghion, Philippe, Christopher Harris, and John Vickers (1997), "Competition and Growth with Step-by-Step Innovation: An Example," European Economic Review, 41, 771-782.

[4] Aghion, Philippe, Christopher Harris, Peter Howitt and John Vickers (2001), "Competition, Imitation and Growth with Step-by-Step Innovation," Review of Economic Studies 68(3), 467-492

[5] Bessen, James, and Eric Maskin (2009), "Sequential Innovation, Patents, and Imitation," RAND Journal of Economics 40 (4), 611-635.

[6] Banal-Estanol, A. and I. Macho-Stadler (2010), "Scientific and Commercial Incentives in R\&D: Research versus Development?" Journal of Economics and Management Strategy 19:185-221.

[7] Bloom, Nicholas, and John Van Reenen (2007), "Measuring and Explaining Management Practices Across Firms and Countries," Quarterly Journal of Economics 122(4), 1351-1408.

[8] Chang, Howard F. (1995) "Patent Scope, Antitrust Policy and Cumulative Innovation." RAND Journal of Economics 26, 34-57.

[9] Dasgupta, Partha and Joseph Stiglitz (1980), "Uncertainty, Industrial Structure, and the Speed of R\&D," The Bell Journal of Economics 11, 1-28.

[10] Erkal, Nisvan and Suzzane Scotchmer (2009), "Scarcity of Ideas and R\&D Options: Use It, Lose It or Bank It," NBER Working Paper 09-14940.

[11] Gallini, Nancy T. (1992), "Patent Policy and Costly Imitation," RAND Journal of Economics 23 (1), 52-63.

[12] Green, Jerry, and Scotchmer, Suzzane (1995), "On the Division of Profit in Sequential Innovation," RAND Journal of Economics, 26, 20-33. 
[13] Gilbert, Richard J., and Carl Shapiro (1990), "Optimal Patent Length and Breadth," RAND Journal of Economics 21(1), 106-12.

[14] Harris, Christopher and John Vickers (1987), "Racing with Uncertainty," Review of Economic Studies 54, 1-21.

[15] Hopenhayn, Hugo, Gerard Llobet and Matthew Mitchell (2006), "Rewarding Sequential Innovators: Prizes, Patents, and Buyouts," Journal of Political Economy 114: 6, 1041-1068.

[16] Hopenhayn, Hugo, and Matthew Mitchell (2011), "Optimal Patent Policy with Recurrent Innovators," working paper, University of Toronto.

[17] Hunt, R. (2004), "Patentability, Industry Structure, and Innovation," Journal of Industrial Economics 52, 401-425.

[18] Klemperer, Paul (1990), "How Broad Should the Scope of Patent Protection Be?" RAND Journal of Economics 21(1), 113-130.

[19] Klette, Tor Jakob, and Samuel Kortum (2004), "Innovating Firms and Aggregate Innovation," Journal of Political Economy 112 (5), 986-1018.

[20] Kremer, Michael (1998), "Patent Buyouts: A Mechanism for Encouraging Innovation," Quarterly Journal of Economics 113 (4): 1137-1167.

[21] Merges Robert P., and Richard R. Nelson (1990), "On the Complex Economies of Patent Scope," Columbia Law Review 90 (4), 839-916.

[22] Nordhaus, William (1969), Invention, Growth and Welfare: A Theoretical Treatment of Technological Change, Cambridge, MA, MIT Press.

[23] O'Donoghue, Ted (1998) "A Patentability Requirement for Sequential Innovation," RAND Journal of Economics 29, 654-679.

[24] O'Donoghue, Ted, Scotchmer, Suzzane, and Thisse, Jacques-François (1998), "Patent Breadth, Patent Life, and the Pace of Technological Progress," Journal of Economics and Management Strategy, 7(1), 1-32.

[25] Posner, Richard (1975), "The Social Costs of Monopoly and Regulation," Journal of Political Economy 83 (4), 807-828.

[26] Reinganum, Jennifer (1982), "A Dynamic Game of R\&D: Patent Protection and Competitive Behavior," Econometrica 50(3), 671-88. 
[27] Sannikov, Yuliy (2008), "A Continuous-Time Version of the Principal-Agent Problem," Review of Economic Studies 75, 957-984.

[28] Scotchmer, Suzanne (1991), "Standing on the Shoulders of Giants," Journal of Economic Perspectives, 5(1), 29-41.

[29] Scotchmer, Suzanne (1996), Protecting Early Innovators: Should Second-Generation Products be Patentable?" RAND Journal of Economics 27, 322-331.

[30] Scotchmer, Suzanne and Jerry Green (1990), "Novelty and Disclosure in Patent Law." RAND Journal of Economics 21, 131-146.

[31] Scotchmer, Suzanne (2011), "Ideas and Innovations: Which Should Be Subsidized?" working paper, University of Berkeley.

[32] Seierstad, Atle and Knut Sydsaeter (1987), Optimal Control Theory with Economic Applications, North-Holland, Amsterdam, Netherland.

[33] Seierstad, Atle (1984), "Sufficient Conditions in Free Final Time Optimal Control Problems: A Comment," Journal of Economic Theory 32, 367-370.

[34] Scherer, F. M. (1972), "Nordhaus's Theory of Optimal Patent Life: A Geometric Reinterpretation," American Economic Review 62 (3), 422-427.

[35] Spear, Stephen E., and Sanjay Srivastava (1987), "On Repeated Moral Hazard with Discounting," Review of Economic Studies 54, 599-617.

[36] Tandon, Pankaj (1982), "Optimal Patents with Compulsory Licensing," Journal of Political Economy 90(3), 470-486. 